\title{
Pulsed Laser Studies of Cationic Reactive Surfactant Radical Propagation Kinetics
}

Thomas R. Rooney, Anna Chovancová, Igor Lacík, * Robin A. Hutchinson*

T. R. Rooney, R. A. Hutchinson

Department of Chemical Engineering, Queen's University, Kingston, ON, K7L 3N6, Canada E-mail: robin.hutchinson@queensu.ca

A. Chovancová, I. Lacík

Polymer Institute of the Slovak Academy of Sciences, Dúbravská cesta 9, 84541 Bratislava, Slovak Republic

E-mail: igor.lacik@savba.sk

Pulsed laser polymerization coupled with size exclusion chromatography (PLP-SEC) was implemented to study the micellar radical homopropagation kinetics of cationic surfmer, polycaprolactone choline iodide ester methacrylate $\left(\mathrm{PCL}_{n} \mathrm{ChMA}\right.$ with $n=2$ average polyester units), at concentrations of 5, 10, and $20 \mathrm{wt} \%$ in aqueous solutions at $25,50,70$, and $85{ }^{\circ} \mathrm{C}$. $\mathrm{PCL}_{2} \mathrm{ChMA}$ can propagate in both aqueous and compartmentalized phases, with the relative importance of the two reaction loci changing with temperature. As the corresponding saturated macromonomer concentration, $[M]$, inside the growing polymeric micelles cannot be easily determined, only the product of propagation rate coefficient $\left(k_{\mathrm{p}}\right)$ and $[M]$ are measured by PLPSEC; at $25{ }^{\circ} \mathrm{C}$, a minimum $k_{\mathrm{p}}$ of $863 \pm 95 \mathrm{~L} \cdot \mathrm{mol}^{-1} \cdot \mathrm{s}^{-1}$ is estimated assuming bulk [M]. (Macro)monomer composition drifts for batch acrylamide (AM)/PCLnChMA micellar copolymerizations in $\mathrm{D}_{2} \mathrm{O}$ at $50^{\circ} \mathrm{C}$ are well represented by the apparent reactivity ratios $r \mathrm{Am}=0.31$ \pm 0.03 and $r$ PCL3ChMA $=8.79 \pm 0.38$.

Keywords: macromonomer; radical polymerization kinetics; surfmer 


\section{Introduction}

Polyelectrolytes are unique among polymers because their ionic character allows them to participate in long-range Coulombic interactions which can be exploited for many applications. ${ }^{1}$ In particular, cationic polyelectrolytes (i.e., polycations) find uses in diverse areas as flocculants, ${ }^{2,3}$ as anti-microbial devices, ${ }^{4}$ and in gene therapy. ${ }^{5}$ In many cases, the charge density as well as the hydrophobic content of the polyelectrolyte are important parameters which need to be carefully designed in order to control performance. ${ }^{6}$ The charge density along the polyelectrolyte backbone can be tuned via aqueous radical copolymerization of a cationic monomer with non-ionic hydrophilic monomers such as acrylamide (AM) ${ }^{7,8}$ while the hydrophobic content may be adjusted via a technique known as micellar radical polymerization (MRP). ${ }^{9}$ In MRP, the hydrophobic monomer may be solubilized in an appropriate surfactant solution, or a reactive surfactant (surfmer) may be polymerized. ${ }^{10-12}$

In the former version of MRP, the copolymers are produced with blocky hydrophobic microdomains whose lengths depend on the intrinsic reactivity of the hydrophobic/hydrophilic comonomers as well as the so-called micellar effect in which the reactivity of the hydrophobic monomer is enhanced due to its compartmentalization..$^{13}$ The micellar effect extends to surfmer polymerization as surfmers form micelles which give rise to elevated polymerization rates and high molecular weight (MW) materials above their critical micelle concentration (CMC) ${ }^{14}$ whereas polymerizations below the CMC are very inefficient. ${ }^{15}$ The large MWs produced by surfmer MRP can be explained in part by the high local concentration of compartmentalized polymerizable groups, but also by the observation that preservation of micelle structure after polymerization is highly unlikely because the rate of surfmer exchange between micelles is much faster than the rate of radical propagation. ${ }^{16,17}$ In other words, despite continuous nucleation and 
dynamic reorganization of the system, surfmer MRP is similar to emulsion radical polymerization in that a saturated monomer concentration inside the growing particle is maintained by monomer diffusion from a reservoir.

Indeed, for the MRP of cationic tail-type surfmer, $\omega$ methacryloyloxyundecyltrimethylammonium bromide (MUTAB), with concentration twice its $\mathrm{CMC}$ at $25^{\circ} \mathrm{C}$, Chatjaroenpron et al. showed that the presence of unpolymerized MUTAB micelles and a constant concentration of free aqueous MUTAB were maintained up to $\approx 50 \%$ conversion, confirming that poly(MUTAB) micelles grow at the expense of the unpolymerized ones. ${ }^{18}$ In terms of morphology, unpolymerized and fully polymerized MUTAB micelles are spheroidal (i.e., geometries with long and short radii ranging roughly from 10-100 $\AA$ and 10-20 , respectively), while at intermediate conversions rod-like mixed polymer/monomer micelles (with length and cross-section radius ranging roughly from $200-3000 \AA$ and $10-30 \AA$, respectively) coexist in dynamic equilibrium with unpolymerized micelles. ${ }^{18-20}$ The structures of poly(MUTAB) systems are also sensitive to environmental factors, responding dynamically and reversibly to temperature, counterion, and salt addition. ${ }^{21}$ Furthermore, as suggested by Hamid and Sherrington, ${ }^{22}$ cationic tail-type surfmers, such as MUTAB, can adopt a "looped" or "hairpin" conformation where both cationic head and polar methacrylate tail reside at the micelle/water interface. The extent to which the methacrylate group partitions to the micelle/water interface instead of the micelle core depends on conditions like temperature and counterion, ${ }^{23}$ and it could be that its radical propagation behavior is different at the two sites. Although many recent works have been devoted to understanding the self-assembly behaviors of surfmers, ${ }^{21}$ there are currently no studies to estimate individual propagation rate coefficients $\left(k_{\mathrm{p}}\right)$ for these intricate systems. 
The pulsed-laser polymerization coupled with size exclusion chromatography (PLP-SEC) technique is the most reliable and accurate method to evaluate $k_{\mathrm{p}}$ and is described by Beuermann and Buback in comprehensive detail. ${ }^{24}$ The product of $k_{\mathrm{p}}$ and monomer concentration, [M], is estimated according to Eqn. 1, where $L_{\mathrm{i}}$, determined by SEC, is a measure of the number of propagation steps of a growing macroradical that survived $i$ dark periods during a low-conversion PLP experiment, and $t_{0}$ is the time between pulses.

$$
\frac{L_{i}}{t_{0}}=i \cdot k_{p}[M]
$$

The IUPAC subcommittee on "Modeling of Polymerization Kinetics and Processes" has benchmarked Arrhenius parameters that describe family behavior for the bulk $k_{\mathrm{p}}$ of methyl methacrylate (MMA) and other alkyl ester methacrylates, ${ }^{25,26}$ where an increase in linear length of the ester side chain correlates with an increase in bulk $k_{\mathrm{p}}$. However, the study of aqueous propagation kinetics is not as straightforward due to the added complexities of aqueous phase SEC analysis, ${ }^{27}$ and significant solvent effects on $k_{\mathrm{p}}{ }^{28}$ For example, entropic reasons dictate that the $k_{\mathrm{p}}$ for non-ionized water-soluble monomers, such as methacrylic acid (MAA), increases sharply towards low monomer concentrations, ${ }^{29-36}$ while the activation energy $\left(E_{\mathrm{A}}\right)$ of partially and fully ionized MAA decreases towards higher monomer concentrations corresponding to greater ionic strengths. ${ }^{37}$

To date, the successful application of PLP-SEC to a cationic monomer system has not been reported. The main challenge is the ionic repulsion in the system which significantly reduces the probability of termination of growing polycations, and therefore restricts the PLP technique to a narrow range of operating conditions known as the low-termination limit (LTL). ${ }^{38-40}$ Thus, Kattner et al. recently developed a new technique combining a single laser initiated pulse with time 
resolved electron paramagnetic resonance (SP-PLP-EPR) to measure the $k_{\mathrm{p}}$ of $20 \mathrm{wt} \%$ [2(methacryloyloxyl)ethyl]trimethylammonium chloride (TMAEMC) in $\mathrm{D}_{2} \mathrm{O}$; a value of 3,500 $\mathrm{L} \cdot \mathrm{mol}^{-1} \cdot \mathrm{s}^{-1}$ at $60{ }^{\circ} \mathrm{C}$ was determined, ${ }^{41}$ while the corresponding $E_{\mathrm{A}}$ and pre-exponential of $15 \pm 1$ $\mathrm{kJ} \cdot \mathrm{mol}^{-1}$ and $(7.9 \pm 0.5) \times 10^{5} \mathrm{~L} \cdot \mathrm{mol}^{-1} \cdot \mathrm{s}^{-1}$, respectively, were estimated using two independent treatments of conversion profiles from chemically initiated batch homopolymerizations. ${ }^{42}$ Furthermore, although PLP-SEC has been implemented in heterogeneous systems to deduce the local styrene concentration compartmentalized in microemulsion droplets, ${ }^{43}$ latex particles, ${ }^{44,45}$ and vesicle structures ${ }^{46}$ PLP-SEC has not yet been applied to estimate $k_{\mathrm{p}}$ for a self-assembled reactive surfactant system. In this work, the PLP-SEC technique is applied to the cationic tail-type surfmer, polycaprolactone choline iodide ester methacrylate ( $\left.\mathrm{PCL}_{n} \mathrm{ChMA}\right)$, a macromonomer system with easily tunable cation/hydrophobic content developed to produce flocculants that promote rapid settling of suspended solids and also enhance sediment dewaterability in response to hydrolytic degradation. ${ }^{47}$ The structure of $\mathrm{PCL}_{n} \mathrm{ChMA}$ is shown in Scheme 1 alongside TMAEMC (chloride counterion) and TMAEMI (iodide counterion) which correspond to $\operatorname{PCL}_{n}$ ChMA macromonomers with $n=0$ polycaprolactone units. Finally, with the aim of further controlling the cation density of poly $\left(\mathrm{PC} \mathrm{L}_{n} \mathrm{ChMA}\right)$ materials, the batch copolymerization kinetics for $\mathrm{PCL}_{\mathrm{n}} \mathrm{ChMA}$ and $\mathrm{AM}$, a common comonomer in flocculants, are also investigated.

TMAEMC<smiles>C=C(C)C(=O)OCC[N+](C)(C)Cl</smiles>

TMAEMI<smiles>C=C(C)C(=O)OCC[N+](C)(C)C</smiles>

AM<smiles>C=CC(N)=O</smiles>

$\mathrm{PCL}_{n} \mathrm{ChMA}$

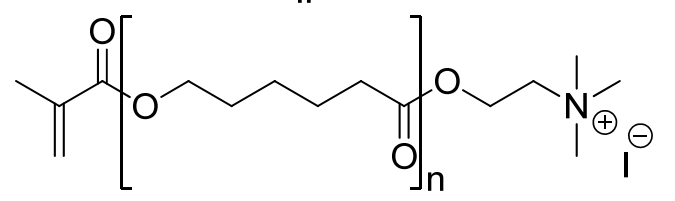

Scheme 1: Chemical structures for (macro)monomers relevant to this work. 


\section{Experimental}

\section{Materials}

E-Caprolactone (CL, 97\%), 2-(dimethylamino)ethanol (De, >98\%), stannous octoate ( $\mathrm{Sn}(\mathrm{oct}) 2$, 92.5-100.0\%) triethylamine (TEA, $\geq 99.5 \%$ ), dimethylformamide (DMF, 99.8\%), formic acid (FA, 98.0-100\%), basic alumina (Brockmann 1), methyl iodide $\left(\mathrm{ICH}_{3}, 99 \%\right.$ ), acrylamide (AM, $\geq 99 \%$ ), sodium chloride ( $\mathrm{NaCl}, \geq 99.0 \%$ ), 2,2-dimethoxy-2-phenylacetophenone (DMPA, 99\%), and 2,2azobis(2-methylpropionamidine)dihydrochloride (V-50, 97\%) were purchased from Sigma Aldrich and used as received. Tetrahydrofuran (THF, $>99 \%$, ACP Chemicals), anhydrous diethyl ether ( $\geq 99.0 \%$, ACP Chemicals), lithium bromide ( $\mathrm{LiBr}, 99+\%$ for analysis, anhydrous, Acros), lithium phenyl-2,4,6-trimethylbenzoylphosphinate (LiTPO, synthesized by R. Liska group Institute of Applied Synthetic Chemistry, Vienna University of Technology, Austria) chloroform$\mathrm{d}\left(\mathrm{CDCl}_{3}, 99.8 \% \mathrm{D}\right.$, Cambridge Isotope Laboratories), and deuterium oxide $\left(\mathrm{D}_{2} \mathrm{O}, 99.9 \% \mathrm{D}\right.$, Cambridge Isotope Laboratories) were used as received. Methacryloyl chloride (MACl, 97\%, Sigma Aldrich) was distilled immediately before use. Ultrapure water was obtained from Ultrapure Water System NW Series (Heal Force Bio-Meditech Holdings, Ltd., China).

\section{Macromonomer Syntheses and Characterizations}

The syntheses of polycaprolactone 2-( $N, N$-dimethylamino)ethyl ester methacrylate $\left(\mathrm{PCL}_{n} \mathrm{DeMA}\right)$ with average $n=2$ and $n=3$ were performed according to a previously published procedure ${ }^{47}$ modified to reduce reaction time. For the synthesis of $\mathrm{PCL}_{2} \mathrm{ChMA}$, a catalyst/monomer mixture with molar ratio of 1:500 consisting of $\mathrm{Sn}(\mathrm{oct}) 2(35.1 \mathrm{mg}, 86.6 \mu \mathrm{mol})$ and CL (4.94 g, $43.3 \mathrm{mmol})$, was loaded into a $50 \mathrm{~mL}$ sealed round bottom flask, purged with nitrogen, and then heated to 130 ${ }^{\circ} \mathrm{C}$. De (1.93 g, $\left.21.7 \mathrm{mmol}\right)$ was added to the catalyst/monomer mixture by syringe and allowed to 
react for $110 \mathrm{~min}$ at $130^{\circ} \mathrm{C}$ to yield polycaprolactone 2 -( $N, N$-dimethylamino)ethyl ester (PCL $\left.2 \mathrm{De}\right)$ with number average $n=2.0$ and CL conversion $\approx 94 \%$ (as determined by ${ }^{1} \mathrm{H}-\mathrm{NMR}$ in Figure S1).

Next, in a sealed 3 neck $100 \mathrm{~mL}$ round bottom flask, $\mathrm{PCL}_{2} \mathrm{De}(6.87 \mathrm{~g}, 21.7 \mathrm{mmol}-\mathrm{OH})$ was dissolved in $35 \mathrm{~mL}$ THF to which $24 \mathrm{~mL}$ TEA $(173.0 \mathrm{mmol})$ was then added. The solution was cooled to $0{ }^{\circ} \mathrm{C}$ using an external ice bath, bubbled with $\mathrm{N}_{2}$ for 10 minutes, and then $2.8 \mathrm{~mL}$ freshly distilled $\mathrm{MACl}(28.2 \mathrm{mmol})$ diluted by $4.1 \mathrm{~mL}$ THF was fed over $1 \mathrm{~h}$ using a glass syringe. The reaction mixture was maintained at $0{ }^{\circ} \mathrm{C}$ for an additional $3 \mathrm{~h}$, filtered to remove the TEA salt, and then passed through a column of basic alumina. The solvent was evaporated in vacuo to afford $6.19 \mathrm{~g}$ polycaprolactone 2-( $N, N$-dimethylamino)ethyl ester methacrylate ( $\left.\mathrm{PCL}_{2} \mathrm{DeMA}\right)$ in $74 \%$ yield including $\mathrm{MACl}$ impurities (Figure S2).

$\mathrm{PCL}_{2} \mathrm{DeMA}(6.19 \mathrm{~g}, 16.1 \mathrm{mmol})$ was dissolved in $140 \mathrm{~mL}$ diethyl ether, cooled to $0{ }^{\circ} \mathrm{C}$ using an external ice bath, and kept under constant flow of nitrogen. Approximately $3 \mathrm{~mL} \mathrm{ICH} 3$ (48.2 mmol) was injected by syringe then the reaction was allowed to warm to room temperature and proceed for $48 \mathrm{~h}$. The white waxy precipitate was collected by filtration, washed three times with $200 \mathrm{~mL}$ cold diethyl ether, and dried in a vacuum oven at $40{ }^{\circ} \mathrm{C}$ overnight to afford $5.48 \mathrm{~g}$ polycaprolactone choline iodide ester methacrylate ( $\left.\mathrm{PCL}_{2} \mathrm{ChMA}\right)(77 \%$ methylation yield). According to the ${ }^{1} \mathrm{H}-\mathrm{NMR}$ in Figure S3, the $\mathrm{PCL}_{2} \mathrm{ChMA}$ macromonomer contains up to $10 \mathrm{~mol} \%$ [2-(methacryloyloxyl)ethyl]trimethylammonium iodide (TMAEMI), resulting from unreacted De initiator in the ROP step, whereas PCL $\mathrm{C}_{3} \mathrm{ChMA}$ does not contain any TMAEMI $\left({ }^{1} \mathrm{H}\right.$ NMR in Figure S4).

All ${ }^{1} \mathrm{H}$ NMR characterizations (Figures S1-S4) were performed on a Bruker Avance instrument operating at $400 \mathrm{MHz}$. The oligomeric distributions of $\mathrm{PCL}_{n}$ DeMA (Figure S5) were assessed by size exclusion chromatography (SEC). The SEC setup consists of a Waters 2960 
separation module instrument with a Waters 410 differential refractometer (DRI), and four Styragel columns (HR $0.5,1,3,4)$ maintained at $35^{\circ} \mathrm{C}$ with distilled THF as eluent at $0.3 \mathrm{~mL} \cdot \mathrm{min}^{-}$

1. The DRI detector was calibrated using 14 narrow poly(MMA) standards (302-853,000 Da).

As shown in Figure $\mathrm{S} 6$, the solid $\mathrm{PCL}_{2} \mathrm{ChMA}$ salt was dissolved as various weight fractions in DMF, and the solution densities were measured between temperatures of 25 and $70{ }^{\circ} \mathrm{C}$ using a Paar DMA 48 Density Meter. Assuming volume additivity, the densities of the $\mathrm{PCL}_{2} \mathrm{ChMA}$ salt were extrapolated at each temperature (Table S1), and subsequently fit by linear regression as summarized by Table 1. The CMC of $\mathrm{PCL}_{n}$ ChMA macromonomers in $\mathrm{H}_{2} \mathrm{O}$ solutions were determined by surface tension measurements (Figures S8 and S17) using a Wilhelmy plate setup (TensioCAD with platinum plate EN14370).

The particle size distributions (PSD) and polydispersity indices (PDI) for $10 \mathrm{wt} \%$ PCL 2 ChMA dispersions in $\mathrm{H}_{2} \mathrm{O}$ were determined with a Malvern Zetasizer Nano ZS (size range $0.3 \mathrm{~nm}-10 \mu \mathrm{m})$ at 25 and $70^{\circ} \mathrm{C}$ with backscattering optics $\left(173^{\circ}\right)$, using a $4 \mathrm{~mW} \mathrm{He}-\mathrm{Ne}(633 \mathrm{~nm})$ laser. All samples were measured in DTS0012 disposable cuvettes. The reported sizes represent an intensity average of at least 30 scans.

\section{Pulsed Laser Polymerization}

Macromonomer solutions were prepared as 5, 10, and $20 \mathrm{wt} \%$ by mixing with $\mathrm{H}_{2} \mathrm{O}$ containing 10 $\mathrm{mmol} \cdot \mathrm{L}^{-1} \mathrm{LiTPO}$, a water soluble photoinitiator. Some solutions were also prepared with sparingly water soluble DMPA, which was added at a concentration of $10 \mathrm{mmol} \cdot \mathrm{L}^{-1}$ relative to the macromonomer, then mixed with water and stirred overnight. As previously described, ${ }^{35}$ PLPs were carried out using an excimer laser (ExciStar XS 500, Coherent, Inc.) operated at $351 \mathrm{~nm}$ and equipped with corona preionization and an all-solid-state-pulser. Pulse repetition rates from 5-50 $\mathrm{Hz}$ were used at a laser energy of $3 \mathrm{~mJ} / \mathrm{pulse}$. The polymerizations were carried out in a $110 \mathrm{OS}$ 
cell (Hellma GmbH \& Co. KG, Germany) of $10 \mathrm{~mm}$ path length. The cell was filled with $1 \mathrm{~mL}$ solution, sealed with a PTFE stopper, and subjected to polymerization. The beam expander BXUV-10.0-3X (CVI Melles Griot, USA) was placed between the laser and the cell to extend the beam so as to homogeneously illuminate the solution. Prior to applying the laser pulses, the macromonomer solutions were thermostated for 10 minutes (at $25,50,70$, or $85{ }^{\circ} \mathrm{C}$ ) before insertion of the cell into the thermostated metallic cell holder where the laser pulses were applied. No significant hydrolysis of the macromonomer (or resulting polymer) is expected during the timeframe of a PLP experiment under these conditions. ${ }^{47}$ After pulsing, the reaction mixture was poured into a vial containing a few crystals of hydroquinone monomethyl ether to suppress postpolymerization. The polymer was isolated by dialysis using SpectraPor tubing with a molar mass cutoff at $3500 \mathrm{Da}$ (Spectra/Por 6, Spectrum Laboratories, Inc., Compton, CA), freeze-dried using a Mini-Lyotrap (LTE Scientific, Greenfield, UK), and then conversion was determined by gravimetry. The dried polymer samples were stored in the dark at $4{ }^{\circ} \mathrm{C}$.

For SEC analysis of the PLP generated polymers, an aqueous eluent of $0.3 \mathrm{M}$ formic acid with $0.3 \mathrm{wt} \% \mathrm{LiBr}$ was selected to ensure good solubility of the cationic polymers and to provide sufficient screening of polyelectrolyte charges. The samples were dissolved in the eluent at concentrations of $1-3 \mathrm{mg} \cdot \mathrm{mL}^{-1}$ by stirring for $24-48$ hours and filtered via a $0.45 \mu \mathrm{m}$ nylon membrane filter (Millex-HN, Millipore, Ireland) prior to injection of $100 \mu \mathrm{L}$ polymer solutions on the columns. SEC was performed using a column setup consisting of PSS NOVEMA Max $8 \times 50$ mm guard and three PSS NOVEMA Max $8 \times 300$ mm $100+1000+3000 \AA$ columns with $10 \mu \mathrm{m}$ particle size (Polymer Standards Service, Mainz, Germany), which was positioned in the column heater at $40{ }^{\circ} \mathrm{C}$. The flow rate of $1.0 \mathrm{~mL} \cdot \mathrm{min}^{-1}$ was controlled by using ethylene glycol as the flow marker. A Waters SEC setup (degasser, 515 pump, column heater, differential RI detector 2410, 
autosampler 717) with SLD 7000 MALLS detector (Polymer Standards Service, Mainz, Germany) was used. The PSS WinGPC ${ }^{\mathbb{B}}$ UniChrom (Polymer Standards Service, Mainz, Germany) software was employed for data acquisition and evaluation. The differential refractive index values $(\mathrm{d} n / \mathrm{d} c)$ were determined by integration of the RI signals from injection of five poly $\left(\mathrm{PCL}_{n} \mathrm{ChMA}\right)$ solutions with concentrations of $0.1-10.0 \mathrm{mg} \cdot \mathrm{mL}^{-1}$ using WinGPC ${ }^{\circledR} \mathrm{UniChrom}$ software. The $\mathrm{d} n / \mathrm{d} c$ values for poly $\left(\mathrm{PCL}_{2} \mathrm{ChMA}\right)$ and poly $\left(\mathrm{PCL}_{3} \mathrm{ChMA}\right)$ are contained in Table 1. An effective calibration was established using nine narrow pullulan standards between 180-830,000 $\mathrm{g} \cdot \mathrm{mol}^{-1}$ (Polymer Laboratories, UK), while pullulan of $113,000 \mathrm{~g} \cdot \mathrm{mol}^{-1}$ was used as an isotropic scatterer to calibrate the MALLS detector.

Table 1: Monomer and polymer parameters relevant to $k_{\mathrm{p}}$ determination by PLP-SEC.

\begin{tabular}{ccccc}
\hline & \multicolumn{3}{c}{ Monomer } & Polymer \\
\cline { 2 - 5 } & $n$ & $\rho\left(\mathrm{g} \cdot \mathrm{mL}^{-1}\right)$ & $\mathrm{CMC}^{\mathrm{b}}\left(\mathrm{mmol} \cdot \mathrm{L}^{-1}\right)$ & $\mathrm{d} n / \mathrm{d} c^{\mathrm{c}}\left(\mathrm{mL} \cdot \mathrm{g}^{-1}\right)$ \\
\hline PCL 2 ChMA & 2.0 & $-0.0006 \cdot T /{ }^{\circ} \mathrm{C}+1.3181^{\mathrm{a}}$ & $1.5(793 \mathrm{ppm})$ & 0.114 \\
PCL 3 ChMA & 3.2 & - & $0.51^{47}(328 \mathrm{ppm})$ & 0.117 \\
AM & - & - & - & 0.155 \\
Pullulan & - & - & - & 0.136 \\
\hline
\end{tabular}

${ }^{\mathrm{a}}$ Pure component value extrapolated from DMF solutions assuming volume additivity. ${ }^{\mathrm{b}}$ measured at room temperature. ${ }^{\mathrm{c}}$ determined in $0.3 \mathrm{M}$ formic acid with $0.3 \mathrm{wt} \% \mathrm{LiBr}$ aqueous eluent.

The SEC traces from the RI detector in Figure S9 do not show any significant concentration dependence which verifies the appropriateness of the current SEC setup to separate poly $\left(\mathrm{PCL}_{\mathrm{n}} \mathrm{ChMA}\right)$ samples based on size. The pullulan calibration is used throughout this work, and the MALLS estimates are only provided if good agreement between at least 2 injections of the same sample was achieved. Otherwise, the $k_{\mathrm{p}} \cdot[M]$ values from analysis of the MMDs were estimated by applying a constant ratio of $1.82 \pm 0.09$, as determined from a comparison (Table S3) of absolute MALLS-RI calibration to the effective calibration established with pullulan standards and RI detection, which exhibits good agreement for select samples within an absolute MW range 
of $110,000-415,000 \mathrm{~g} \cdot \mathrm{mol}^{-1}$. Although there appears to be a slight increasing trend in this ratio for some individual higher MW samples, the 1.82 ratio is still implemented to provide insight despite the uncertainty.

\section{Batch Macromonomer Copolymerization Studies}

All AM/PCL $L_{n}$ ChMA copolymerizations were performed in $\mathrm{D}_{2} \mathrm{O}$ (containing $0.22 \mathrm{wt} \% \mathrm{~V}-50$ initiator) at $50{ }^{\circ} \mathrm{C}$ following a previously described procedure for in situ ${ }^{1} \mathrm{H} N \mathrm{NR},{ }^{48}$ using an Agilent Varian instrument operating at $300 \mathrm{MHz}$. (Macro)monomer solutions, with initial AM content of $f_{\mathrm{AM}, 0}=0,0.1,0.5,0.9$, and 1.0 , were prepared at 5 or $10 \mathrm{wt} \%$ concentrations relative to $\mathrm{D}_{2} \mathrm{O}$ and carefully bubbled with $\mathrm{N}_{2}$ for at least $1 \mathrm{~h}$ prior to polymerization. Monomer composition was monitored by comparing the vinyl peak intensity for $\mathrm{AM}$ to that of $\mathrm{PC} \mathrm{L}_{\mathrm{n}} \mathrm{ChMA}$, while conversion was determined via the sum of both (macro)monomers' vinylic integrations relative to the HOD signal as a function of time. The monomer composition drift as a function of conversion data was used to estimate terminal model reactivity ratios via the integrated Mayo-Lewis equation implemented by Predici software. ${ }^{48}$ Finally, SEC of the high conversion batch copolymers was performed using the setup described for PLP-SEC except that samples were injected as $0.5 \mathrm{mg} \cdot \mathrm{mL}^{-}$

${ }^{1}$, the eluent flow rate was $0.25 \mathrm{~mL} \cdot \mathrm{min}^{-1}$, and PSS NOVEMA Max guard $8 \times 50 \mathrm{~mm}$ and two PSS NOVEMA Max Ultrahigh columns with $10 \mu \mathrm{m}$ particle size were implemented. The MALLS output for each sample was interpreted using a mass-weighted composition average of the homopolymer $\mathrm{d} n / \mathrm{d} c$ values reported in Table 1 . 


\section{Results and Discussion}

\section{Pulsed Laser Polymerization}

Due to the micellar nature of $\mathrm{PCL}_{n} \mathrm{ChMA}$ surfmers in aqueous solution and despite their cationic and methacrylic functionalities, quantitative conversion of $\mathrm{PCL}_{3} \mathrm{ChMA}$ polymerization was reached significantly faster than $\mathrm{AM}$ homopolymerization at $50{ }^{\circ} \mathrm{C}$ under similar conditions. ${ }^{47} \mathrm{In}$ comparison to methacrylic monomers, the aqueous propagation of AM is known to be much more rapid, ${ }^{35}$ and therefore PLP-SEC is implemented to specifically investigate the propagation behavior of PCL ${ }_{n} C h M A$ homopolymerization in micellar media. Despite the simplicity of the PLP-

SEC technique, its application to $\mathrm{PCL}_{n} \mathrm{ChMA}$ systems is unusually complicated because of the dynamic coexistence of aqueous and compartmentalized macromonomer phases, the distribution of macromonomer chain lengths, and the $n=0$ TMAEMI form of the macromonomer, (similar to TMAEMC) which is water soluble.

Preliminary $\mathrm{PCL}_{3} \mathrm{ChMA}$ aqueous homopolymerization PLP-SEC experiments performed at $50{ }^{\circ} \mathrm{C}$ with pulse repetition rates of 33 and $50 \mathrm{~Hz}$ yielded molar mass distributions (MMD) whose corresponding $1^{\text {st }}$ derivative plots did not exhibit inflection points characteristic of the PLP technique. This shortcoming is likely related to the relatively high viscosity associated with PCL ${ }_{3}$ ChMA (average MW of $641 \mathrm{~g} \cdot \mathrm{mol}^{-1}$ ), making it a LTL PLP system for which operating conditions that lead to successful $k_{\mathrm{p}}$ determination are limited. ${ }^{38,40}$ Therefore, PLP-SEC experiments for aqueous homopolymerizations of $\mathrm{PCL}_{2} \mathrm{ChMA}$, whose lower average $\mathrm{MW}$ of 527 $\mathrm{g} \cdot \mathrm{mol}^{-1}$ facilitates improved termination relative to $\mathrm{PCL}_{3} \mathrm{ChMA}$, were performed at 25, 50, 70, and $85^{\circ} \mathrm{C}$ with specific reaction conditions as well as both pullulan calibration and MALLS outputs summarized by Tables S4, S5, S6, and S7, respectively. It should be noted that $\mathrm{PCL}_{2} \mathrm{ChMA}_{\text {is a }}$ distribution of macromonomers (Figure S5), with number average $n=2.0$ polyester units, that 
contains up to 10 mol\% TMAEMI (as determined by ${ }^{1} \mathrm{H}$ NMR in Figure S3). The particle size distributions for $10 \mathrm{wt} \%$ macromonomer aqueous solutions at 25 and $70{ }^{\circ} \mathrm{C}$, shown by Figure $\mathrm{S} 7$ provide evidence for $\mathrm{PCL}_{2} \mathrm{ChMA}$ compartmentalization, where the bimodal intensity scattering could indicate that $\mathrm{PCL}_{2} \mathrm{ChMA}$ micelles may have non-spherical geometries, ${ }^{49}$ as was observed for polymer produced by $\mathrm{PC}_{n} \mathrm{ChMA}$ homopolymerization ${ }^{47}$ and as has been documented for micelles of the chemically similar MUTAB surfmer. ${ }^{18-20}$ In addition, the dispersion parameters summarized by Table S2 highlight the dynamic nature of the system; in particular, the decreasing scattering intensity towards higher temperatures indicates increased $\mathrm{PCL}_{2} \mathrm{ChMA}_{\text {aqueous }}$ solubility. Thus, it is likely that the location of the reaction site (aqueous or compartmentalized) changes with temperature such that determination of $[M]$ is not trivial.

Unless otherwise specified, the MMDs for all PLP experiments are presented in terms of pullulan calibration. Figure 1 demonstrates that $\mathrm{PCL}_{2} \mathrm{ChMA}$ homopropagation can be controlled by laser pulsing at various pulse repetition rates and temperatures. In addition, no difference in inflection point locations was detected when a $10 \mathrm{wt} \%$ PCL 2 ChMA sample was pulsed at $20 \mathrm{~Hz}$ and $50{ }^{\circ} \mathrm{C}$ with 10 or $20 \mathrm{mmol} \cdot \mathrm{L}^{-1} \mathrm{LiTPO}$ photoinitiator. It is noteworthy that in Figure 1 there are a significant number of chains terminated prior to the arrival of the subsequent laser pulse, giving rise to a peak with inflection point near $35,000 \mathrm{~g} \cdot \mathrm{mol}^{-1}$, as indicated by $D$ on the $1^{\text {st }}$ derivative plots. The origin of $D$ is unknown yet it does not shift according to pulse repetition rate and only slightly decreases to lower MW at higher temperatures. In addition, inflection point $D$ often obstructs the identification of PLP generated primary inflection points, $L_{1}$, such that the ratio of secondary to primary inflection points, $L_{2} / L_{1}$, is frequently less than 2.0 ; at $30 \mathrm{~Hz}, L_{1}$ and $D$ are completely overlapped and therefore $L_{2}$ is used to evaluate PCL $\mathrm{C}_{2} \mathrm{ChMA}$ PLP experiments performed at relatively low pulse repetition rates in this study, consistent with previous works. ${ }^{36}$ 
Since determination of the macromonomer concentration at the reaction site, $[M]$, is not straightforward for $\mathrm{PCL}_{2} \mathrm{ChMA}$ aqueous homopolymerizations, the evaluation of PLP-SEC experiments are expressed as $k_{\mathrm{p}} \cdot[M]$ in Tables S4-S7.
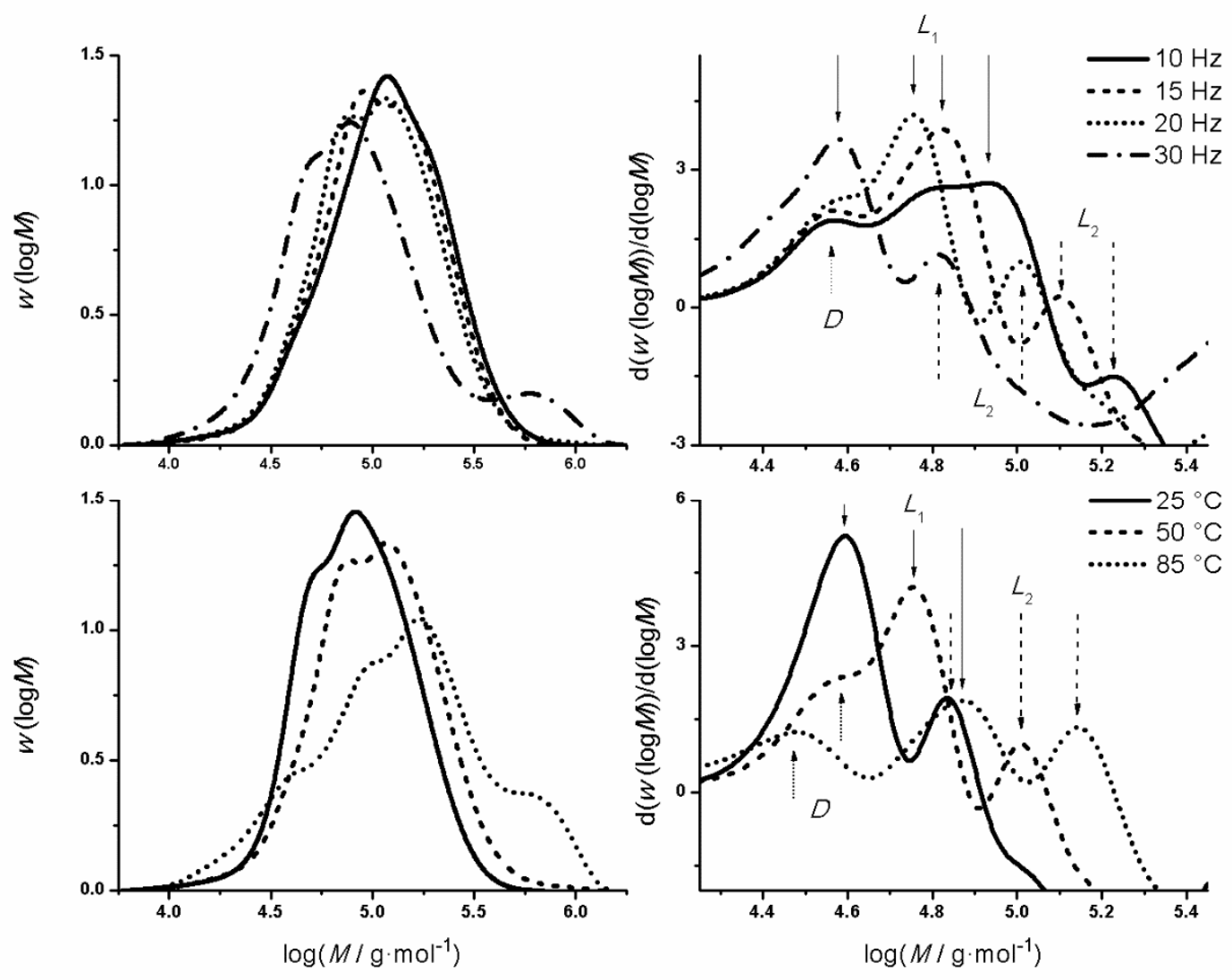

Figure 1: MMDs (left) and corresponding $1^{\text {st }}$ derivative plots (right) according to pullulan calibration for PLP-SEC experiments of $10 \mathrm{wt} \% \mathrm{PCL}_{2} \mathrm{ChMA}$ at $50{ }^{\circ} \mathrm{C}$ and variable pulse repetition rate (top) as well as $10 \mathrm{wt} \% \mathrm{PCL}_{2} \mathrm{ChMA}$ at $20 \mathrm{~Hz}$ and variable temperature (bottom). Inflection points labelled $D$ correspond to the lengths of chains terminated prior to the arrival of a subsequent pulse. The positions of $L_{1}, L_{2}$, and $D$ are denoted by solid downward, broken, and solid upward lines, respectively.

For compartmentalized systems, the aqueous phase monomer concentration is governed by the $\mathrm{CMC}$; if aqueous phase propagation is dominant, addition of salt to lower the CMC should result in a commensurate reduction in $k_{\mathrm{p}} \cdot[M]$ measured by PLP-SEC. To test this hypothesis, PLP 
experiments were performed with $0,1.0$, and $3.4 \mathrm{M} \mathrm{NaCl}$ at $25^{\circ} \mathrm{C}$, as shown by Figure 2 . While addition of $3.4 \mathrm{M} \mathrm{NaCl}$ reduces the $\mathrm{CMC}$ of $\mathrm{PCL}_{2} \mathrm{ChMA}$ at $25^{\circ} \mathrm{C}$ by approximately one order of magnitude (see Figure $\mathrm{S} 8$ ), the concentration of $\mathrm{NaCl}$ has no significant effect on the PLP MMDs at this temperature, certainly not to an extent that would be expected for a ten-fold reduction in aqueous macromonomer concentration. Although the $L_{1}$ positions of the MMDs in Figure 2 are likely overlapped by peak $D$ (as was the case for MMD of the $50{ }^{\circ} \mathrm{C}$ sample performed at $30 \mathrm{~Hz}$ in Figure 1), the positions of $L_{2}$, from which $k_{\mathrm{p}} \cdot[M]$ estimations are made, are plainly unobstructed. Therefore it can be safely assumed that propagation occurs predominantly inside the compartmentalized phase at $25^{\circ} \mathrm{C}$. Also included in Figure 2 are MMDs from PLP experiments conducted without $\mathrm{NaCl}$ at $25^{\circ} \mathrm{C}$ and up to $28 \%$ conversion (conversions are typically kept below $5 \%$ to maintain a near constant monomer concentration throughout a PLP experiment). If the $\mathrm{PCL}_{2} \mathrm{ChMA}$ concentration at the reaction site is not constant, a different $k_{\mathrm{p}}$ measured by PLP-SEC would be expected towards higher conversions. ${ }^{32}$ However, negligible differences in the quality of PLP structure for experiments performed to high conversions suggests that at $25{ }^{\circ} \mathrm{C}$ the compartmentalized propagation occurs at constant macromonomer concentration. Therefore, it is reasonable to assume that during polymerization at $25{ }^{\circ} \mathrm{C}$ (and up to at least $28 \%$ conversion), an equilibrium, or saturated, $\mathrm{PCL}_{2} \mathrm{ChMA}$ concentration at the compartmentalized reaction site is maintained via macromonomer diffusion from unpolymerized micelles. ${ }^{14,17,18}$ 

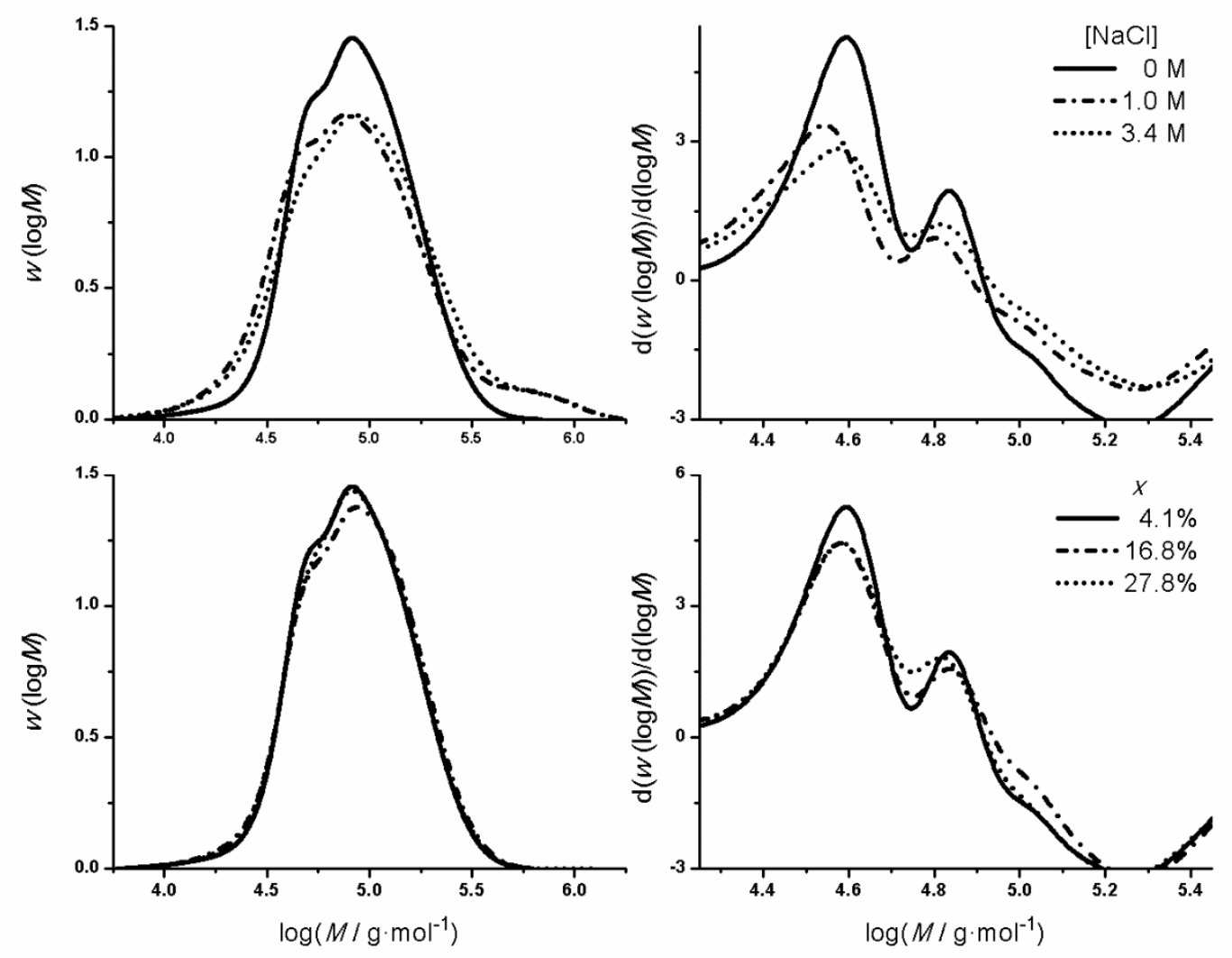

Figure 2: MMDs (left) and corresponding $1^{\text {st }}$ derivative plots (right) according to pullulan calibration for PLP-SEC experiments of $10 \mathrm{wt} \% \mathrm{PCL}_{2} \mathrm{ChMA}$ with $10 \mathrm{mmol} \cdot \mathrm{L}^{-1} \mathrm{LiTPO}$ performed at $25^{\circ} \mathrm{C}$ and $20 \mathrm{~Hz}$ with variable $\mathrm{NaCl}$ concentrations (top) as well as variable conversions (bottom).

Determining the reaction site of $\mathrm{PCL}_{2} \mathrm{ChMA}$ homopropagation at elevated temperatures is more complicated. Recalling that the macromonomer aqueous solubility increases with temperature and that $\mathrm{PCL}_{2} \mathrm{ChMA}$ comprises a distribution of macromonomers with up to $10 \mathrm{~mol} \%$ TMAEMI (Figures S3 and S5), distinct aqueous phase propagation is plausible. Evidence for aqueous phase propagation at elevated temperatures is exhibited by the $85{ }^{\circ} \mathrm{C}$ PLP MMDs in Figure 3, where experiments performed with added $\mathrm{NaCl}$ lead to higher $\mathrm{MW}$ inflection points and thus greater values of $k_{\mathrm{p}} \cdot[M]$. Since the presence of $\mathrm{NaCl}$ reduces the aqueous surfmer 
concentration, the measured increases in $k_{\mathrm{p}} \cdot[M]$ must reflect an increase in the $k_{\mathrm{p}}$ value. Indeed, increased ionic strengths lead to increased rates of fully ionized acrylic acid homopolymerization ${ }^{50}$ as well as a measured decrease in the $E_{\mathrm{A}}$ for $k_{\mathrm{p}}$ of partially and fully ionized MAA aqueous homopropagation systems. ${ }^{37}$ As a further indication that $\mathrm{PCL}_{2} \mathrm{ChMA}$ aqueous propagation is prominent at $85^{\circ} \mathrm{C}$, the secondary (non-PLP) peaks of the MMDs of Figure 3 shift with increasing $\mathrm{NaCl}$ concentrations from $\log M=7.0$ towards $\log M=5.7$ and then to $\log M=4.5$. As these peaks comprise chains whose terminations were not controlled by laser pulsing, the shift to lower MWs may reflect the ability of $\mathrm{NaCl}$ to better screen ionic repulsions between macroradicals so as to increase the probability of termination in the aqueous phase.$^{51}$ Finally, the additional experiments in Figure 3 that were performed at $85^{\circ} \mathrm{C}$ without $\mathrm{NaCl}$ do not exhibit any significant change in inflection point MW (a slight shift to higher MW that is within the experimental error of PLPSEC), indicating that the $\mathrm{PCL}_{2} \mathrm{ChMA}$ macromonomer concentration is still saturated up to $39 \%$ conversion at $85^{\circ} \mathrm{C}$. 

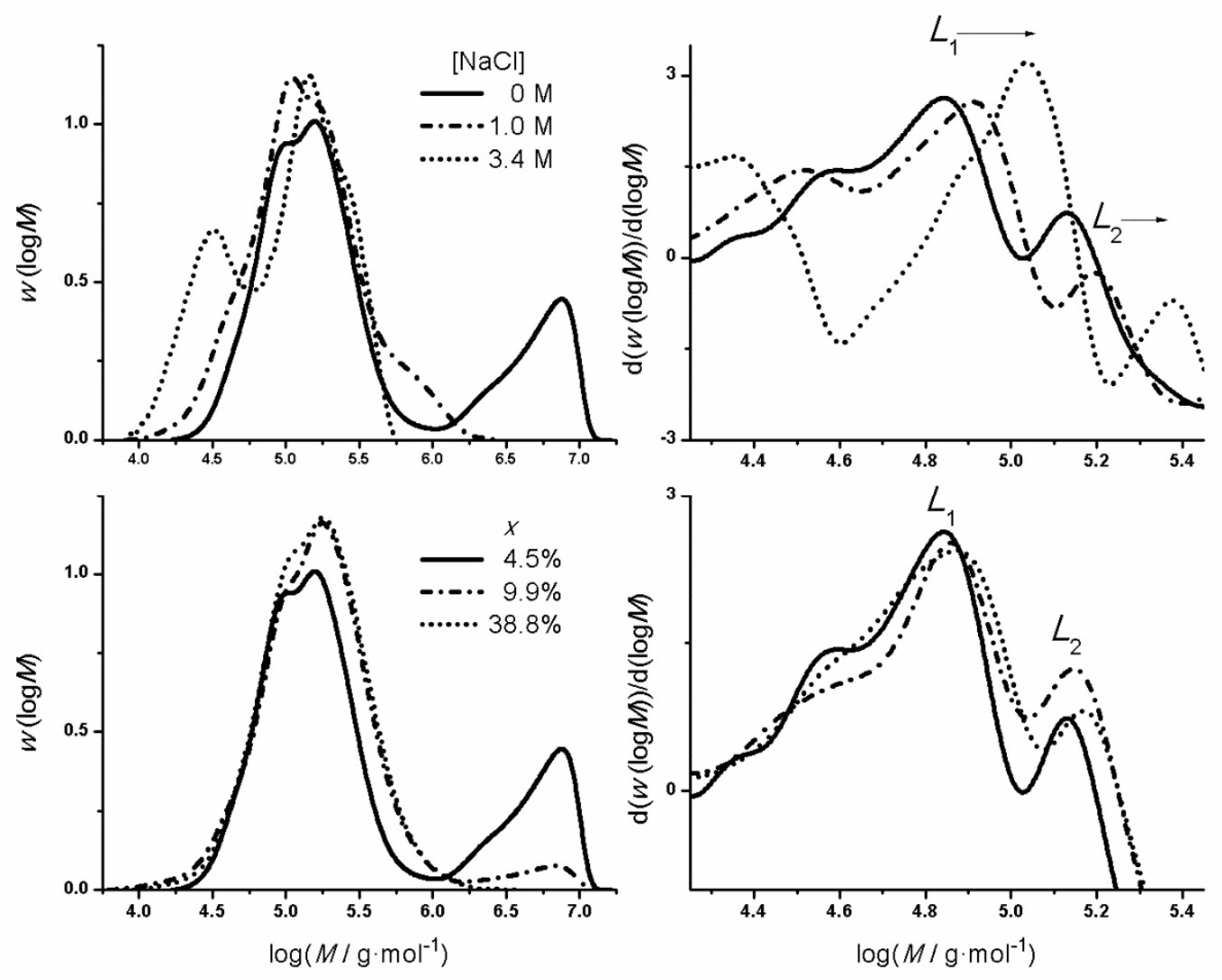

Figure 3: MMDs (left) and corresponding $1^{\text {st }}$ derivative plots (right) according to pullulan calibration for PLP-SEC experiments of $10 \mathrm{wt} \% \mathrm{PCL}_{2} \mathrm{ChMA}$ with $10 \mathrm{mmol} \cdot \mathrm{L}^{-1} \mathrm{LiTPO}$ performed at $85^{\circ} \mathrm{C}$ and $20 \mathrm{~Hz}$ with variable $\mathrm{NaCl}$ concentrations (top) as well as variable conversions (bottom).

In order to further investigate how the $\mathrm{PCL}_{2} \mathrm{ChMA}$ polymerization locus changes with temperature, additional PLP experiments were performed with $10 \mathrm{mmol} \cdot \mathrm{L}^{-1} \mathrm{DMPA}$ (photoinitiator with low aqueous solubility) under otherwise identical conditions at 25,50 , and $70{ }^{\circ} \mathrm{C}$, to contrast to the majority of experiments conducted with $10 \mathrm{mmol} \cdot \mathrm{L}^{-1} \mathrm{LiTPO}$ (high aqueous solubility), with the resulting MMDs presented in Figure 4. At $25{ }^{\circ} \mathrm{C}$ there is almost no difference in PLP structures when different photoinitiators are used, indicating that chains initiated in the aqueous phase quickly nucleate unpolymerized $\mathrm{PCL}_{2} \mathrm{ChMA}$ micelles (micellar nucleation) or precipitate as 
polymeric micelles (similar to homogenous nucleation), and then continue propagation in the compartmentalized phase. On the other hand, at 50 and $70{ }^{\circ} \mathrm{C}$ the inflection points for PLP MMDs shown in Figure 4 are shifted to higher MW when DMPA is used as photoinitiator instead of LiTPO. This indicates that higher temperatures afford enhanced aqueous solubility of the LiTPOinitiated oligomers in the aqueous phase such that the growing chain can spend more time outside of a micelle (where $k_{\mathrm{p}} \cdot[M]$ must be different than inside the micelle) before the reaction locus is transferred to the compartmentalized phase (either by a homogeneous or micellar nucleation mechanism) and before being terminated at the next laser pulse. Lastly, it should be noted that when DMPA is used as photoinitiator the unassigned inflection point $D$ becomes more distinct and shifts towards lower MW, indicating that its origin may be related to termination of chains in the aqueous phase before arrival of the subsequent laser pulse. 

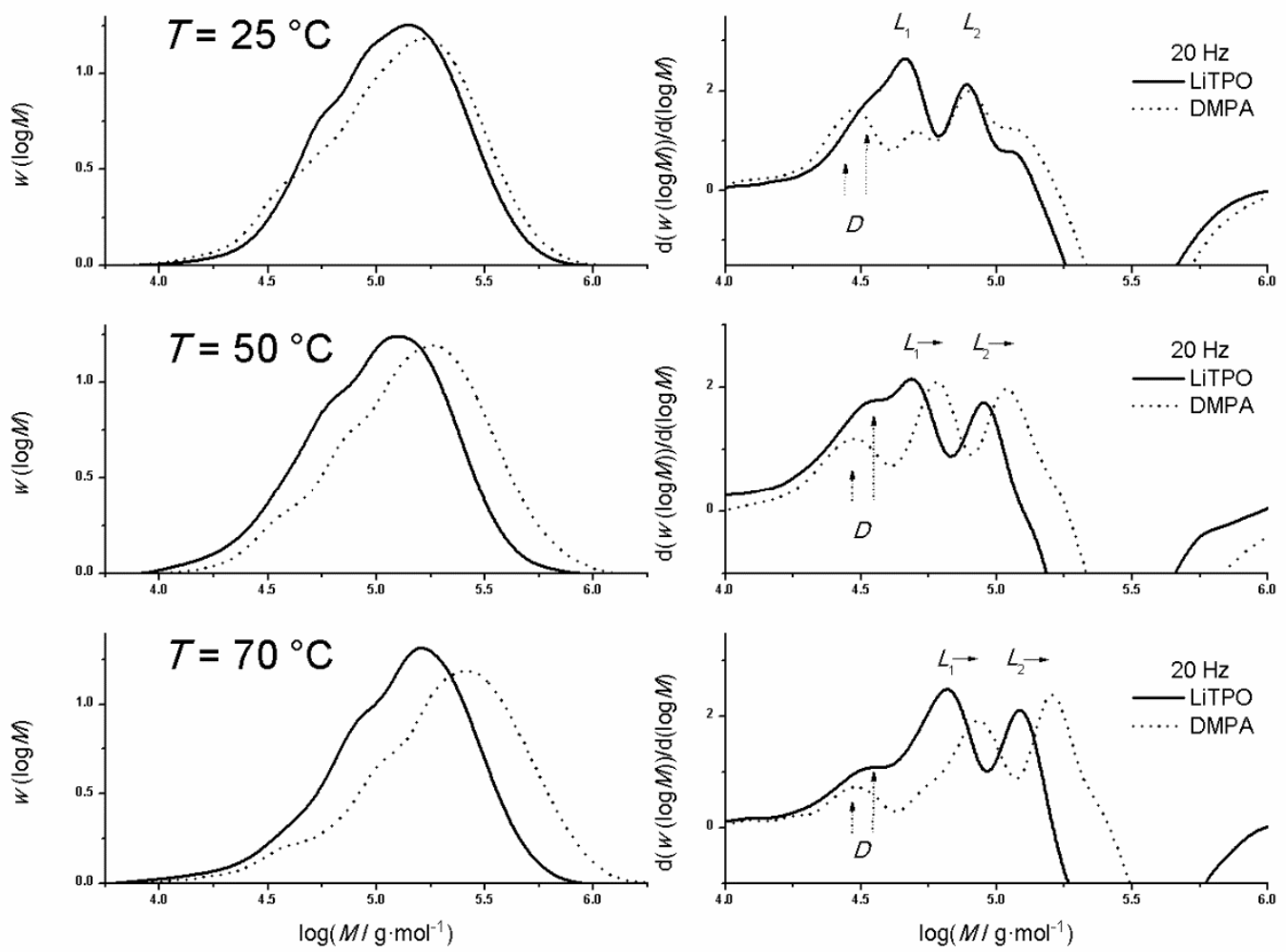

Figure 4: MMDs (left) and corresponding $1^{\text {st }}$ derivative plots (right) according to pullulan calibration for $20 \mathrm{wt} \%$ PCL 2 ChMA PLP-SEC experiments performed at 25 (top), 50 (centre), and $70{ }^{\circ} \mathrm{C}$ (bottom) with $20 \mathrm{~Hz}$ and $10 \mathrm{mmol} \cdot \mathrm{L}^{-1} \mathrm{LiTPO}$ or DMPA as photoinitiator.

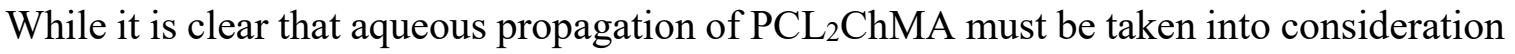
at elevated temperatures, the relative extents of propagation in the aqueous and compartmentalized phases cannot be determined from the current data set. Furthermore, micellar radical copolymerization studies of hydrophobic monomers with water-soluble comonomers demonstrated that the growing chain can alternate between reaction sites such that the two modes of propagation cannot be considered exclusively. ${ }^{9}$ Thus, as detailed by Eqn. 2, an appropriate treatment of the $L_{2}$ values measured by PLP-SEC would account for both the aqueous and compartmentalized phase $k_{\mathrm{p}} \cdot[M]$ contributions as a chain-end radical lifetime-weighted average, 
where $t_{0}$ is the time between successive laser pulses, and $t_{\mathrm{aq}}$ and ( $\left.t_{0}-t_{\mathrm{aq}}\right)$ are the mean lifetimes of a chain-end radical in the aqueous and compartmentalized phases, respectively.

$$
\frac{L_{2}}{2 \cdot t_{0}}=k_{p}[M]=k_{p}^{a q}[M]_{a q}\left(\frac{t_{a q}}{t_{0}}\right)+k_{p}^{c o m p}[M]_{c o m p}\left(\frac{t_{0}-t_{a q}}{t_{0}}\right)
$$

The values of $k_{\mathrm{p}}$ in each phase are expected to be significantly different, as seen be examining data for related systems; at $60{ }^{\circ} \mathrm{C}$ the $k_{\mathrm{p}}{ }^{\mathrm{aq}}$ for $20 \mathrm{wt} \%$ TMAEMC is $3,500 \mathrm{~L} \cdot \mathrm{mol}^{-1} \cdot \mathrm{s}^{-1}$, ${ }^{41}$ whereas the $k_{\mathrm{p}}$ for bulk dodecyl methacrylate is $1,280 \mathrm{~L} \cdot \mathrm{mol}^{-1} \cdot \mathrm{s}^{-1} \cdot{ }^{26}$ However, without knowledge of the extent to which the locus of polymerization changes or the corresponding aqueous and compartmentalized macromonomer concentrations, the treatment detailed by Eqn. 2 cannot be applied. If the saturated monomer and aqueous monomer (CMC) concentrations are determined as a function of temperature, it may be possible to fit the parameters in Eqn. 2 by systematically comparing overall $k_{\mathrm{p}} \cdot[M]$ measured using DMPA and LiTPO at different $\mathrm{NaCl}$ concentrations (with the intent of independently varying the location of radical generation and the aqueous macromonomer concentration at a fixed compartmentalized monomer concentration). In addition, to further elucidate information about the location of propagation, the aforementioned experiments could be extended to include radical traps in either phase. Until then, the compilation of $k_{\mathrm{p}} \cdot[M]$ values (using LiTPO and without added $\mathrm{NaCl}$ ) plotted in Figure 5 as a function of weight fraction macromonomer must be interpreted individually at each temperature; the absolute values in Figure 5 were obtained by applying the 1.82 MALLS correction factor.

Since propagation at $25{ }^{\circ} \mathrm{C}$ was determined to be predominantly compartmentalized with a saturated macromonomer concentration (up to at least $28 \%$ conversion), it is no surprise that the measured $k_{\mathrm{p}} \cdot[M]$ values at $25^{\circ} \mathrm{C}$ appear to be invariant with macromonomer content, similar to a bulk polymerization system. In contrast, the $k_{\mathrm{p}} \cdot[M]$ measured for $5 \mathrm{wt} \% \mathrm{PCL}_{2} \mathrm{ChMA}$ at $50{ }^{\circ} \mathrm{C}$ is 
markedly lower than at 10 and $20 \mathrm{wt} \%$, which is indicative of aqueous phase contributions to the value (Figure 5). If the measured increase from 5 to $10 \mathrm{wt} \%$ was due simply to an increasing monomer concentration, a commensurate increase in $k_{\mathrm{p}} \cdot[M]$ from 10 to $20 \mathrm{wt} \%$ would also be expected, but is not observed. In addition, the scattering intensities measured for $10 \mathrm{wt} \%$ PCL 2 ChMA (Table S2) indicate that a significant amount of $\mathrm{PCL}_{2} \mathrm{ChMA}_{\text {is }}$ still compartmentalized up to $70{ }^{\circ} \mathrm{C}$, meaning that a heterogeneous system with saturated macromonomer concentrations still exists at elevated temperatures. Therefore, the increase in $k_{\mathrm{p}} \cdot[M]$ from 5 to $10 \mathrm{wt} \%$ at $50{ }^{\circ} \mathrm{C}$ likely reflects a true increase in $k_{\mathrm{p}}$ in the aqueous phase, a feature documented for fully ionized MAA propagation kinetics. ${ }^{37}$ At 70 and $85{ }^{\circ} \mathrm{C}$, the limited data sets do not indicate any trend in $k_{\mathrm{p}} \cdot[M]$ as a function of macromonomer weight fraction. 


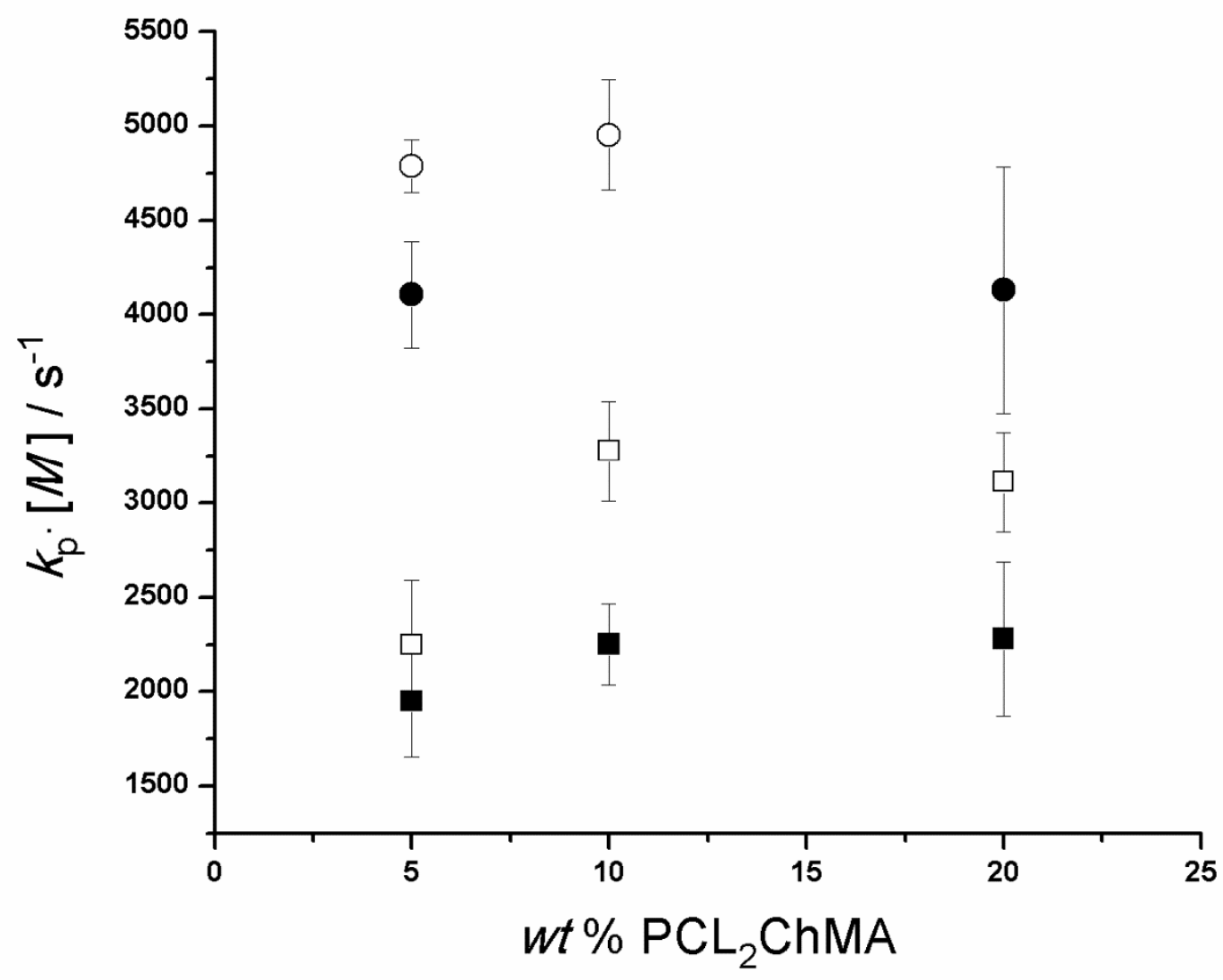

Figure 5: Product of $k_{\mathrm{p}}$ and $[M]$ determined for PLP-SEC experiments performed with various initial $P C L_{2} C h M A$ weight fractions relative to $\mathrm{H}_{2} \mathrm{O}$ containing $10 \mathrm{mmol} \cdot \mathrm{L}^{-1} \mathrm{LiTPO}$ at $25(\square), 50(\square), 70(\bullet)$, and $85^{\circ} \mathrm{C}(\circ)$. Error bars represent standard deviations.

A clear explanation for $\mathrm{PCL}_{2} \mathrm{ChMA}$ propagation behavior at elevated temperatures in Figure 5 cannot yet be provided because of the many complexities related to the system heterogeneity; however, the main features are discussed in order to guide future experiments. As $\mathrm{PCL}_{2} \mathrm{ChMA}$ comprises a distribution of macromonomers (with up to $10 \mathrm{~mol} \% \mathrm{TMAEMI}$ ), the differences in aqueous solubilities and chemical structures of individual components must be taken into account (see Scheme 1). It is speculated that compared to the situation at $25{ }^{\circ} \mathrm{C}$, the contribution of aqueous phase propagation at $50{ }^{\circ} \mathrm{C}$ is significant and dominated by the cationic 
monomer TMAEMI (the component with the greatest aqueous solubility) which would support the resemblance of the $50{ }^{\circ} \mathrm{C} k_{\mathrm{p}} \cdot[M]$ profile's shape in Figure 5 to that of the $k_{\mathrm{p}}$ profile for fully ionized MAA as a function of monomer weight fraction. ${ }^{37}$ Towards higher temperatures, such as 70 and $85^{\circ} \mathrm{C}$, the aqueous solubilities of the low MW PCL 2 ChMA fractions (e.g. individual $n=1$ or $n=2$ chains) increase and it is uncertain whether their aqueous propagation behaviors follow trends for non-ionic or ionic monomer systems. As illustrated by Scheme 1, the quaternary ammonium groups of PCLnChMA oligomers are separated from the methacryloyl carbonyl by $n$ PCL spacers, whereas the quaternary ammonium of TMAEMI is only separated by an ethyl spacer. The ethyl separation of TMAEMC's charged group from its methacrylic ester was proposed as a reason to explain the intermediary pre-exponential estimate for the aqueous $k_{\mathrm{p}}$ of $1.2 \mathrm{~mol} \cdot \mathrm{L}^{-1}$ TMAEMC compared to fully ionized MAA (charge delocalized in the methacrylic ester) and linear alkyl methacrylates (no charge). ${ }^{42}$ In addition, the impact of functionalities far into the methacrylic ester side chain were found to have no additional impact on the bulk $k_{\mathrm{p}}$ of methacrylate macromonomers ${ }^{36,52}$ or their copolymerization behavior with styrene. ${ }^{53}$ Therefore, it is speculated that the $k_{\mathrm{p}} \cdot[M]$ measured at 70 and $85^{\circ} \mathrm{C}$ may represent a sum of ionized (TMAEMI) and nonionized ( $\mathrm{PCL}_{\mathrm{n}} \mathrm{ChMA}$ because of the distance between its quaternary ammonium and methacrylic ester) aqueous as well as compartmentalized propagation behaviors.

The $k_{\mathrm{p}} \cdot[M]$ estimates from 10 and $20 \mathrm{wt} \% \mathrm{PCL}_{2} \mathrm{ChMA}$ homopolymerizations at temperatures between 25 and $85{ }^{\circ} \mathrm{C}$ are summarized by the Arrhenius plot in Figure 6 which was produced by applying the 1.82 MALLS correction factor. Bulk monomer concentrations were assumed at each temperature (see Table S1), as would exist in a micelle in the absence of polymer, in order to estimate minimum $k_{\mathrm{p}}$ values and to calculate an $E_{\mathrm{A}}$ of $12.0 \mathrm{~kJ} \cdot \mathrm{mol}^{-1}$ as well as a preexponential of $1.2 \times 10^{5} \mathrm{~L} \cdot \mathrm{mol}^{-1} \cdot \mathrm{s}^{-1}$. The other relevant limiting case - assuming that all 
macromonomer is dissolved in the aqueous phase - is also considered in Figure 6, yielding a similar estimate of $11.6 \mathrm{~kJ} \cdot \mathrm{mol}^{-1}$ for the activation energy, but an order-of-magnitude higher preexponential factor of $1.3 \times 10^{6} \mathrm{~L} \cdot \mathrm{mol}^{-1} \cdot \mathrm{s}^{-1}$. These curves encompass the $k_{\mathrm{p}}$ values recently reported for $20 \mathrm{wt} \%$ TMAEMC, ${ }^{42}$ as might be expected for a compartmentalized system with both micellar and aqueous phase reaction (see Eqn. 2). The lower observed activation energy compared to the $15 \mathrm{~kJ} \cdot \mathrm{mol}^{-1}$ reported for $\mathrm{TMAEMC}^{42}$ may reflect a lessened contribution from the compartmentalized phase with increasing temperature. However, without temperature dependent information about saturated macromonomer concentrations or extents of aqueous and compartmentalized polymerization loci, a meaningful interpretation of $\mathrm{PCL}_{2} \mathrm{ChMA}_{\text {Arrhenius }}$ parameters cannot be established. Nevertheless, it is worth noting that the estimated $E_{\mathrm{A}}$ for $\mathrm{PCL}_{2} \mathrm{ChMA}$ is well below the values for bulk MMA $\left(22.4 \mathrm{~kJ} \cdot \mathrm{mol}^{-1}\right)^{25}$ and aqueous non-ionized MAA (mean value of $15.6 \mathrm{~kJ} \cdot \mathrm{mol}^{-1}$ ), ${ }^{33}$ yet in a similar range as $5-40 \mathrm{wt} \%$ fully ionized MAA systems $\left(12.4-8.0 \mathrm{~kJ} \cdot \mathrm{mol}^{-1}\right) \cdot{ }^{37}$

As a final analysis, the invariance at $25^{\circ} \mathrm{C}$ of $k_{\mathrm{p}} \cdot[M]$ to $\mathrm{NaCl}$ concentration, monomer conversion, and initiator type justifies the implementation of bulk macromonomer concentration to calculate a minimum $k_{\mathrm{p}}$ at this temperature. There is a high reproducibility in the MALLS data collected for multiple PLP samples produced at $25{ }^{\circ} \mathrm{C}$ (Table S4) such that an absolute minimum value for $k_{\mathrm{p}}$ of PCL $\mathrm{PLhMA}_{2}$ at $25^{\circ} \mathrm{C}$ is calculated as $863 \pm 95 \mathrm{~L} \cdot \mathrm{mol}^{-1} \cdot \mathrm{s}^{-1}$ from the MALLS output of 11 samples. As comparison for PCL $2 \mathrm{ChMA}$, whose average MW is $527 \mathrm{~g} \cdot \mathrm{mol}^{-1}$, PLP-SEC studies of other high MW methacrylates, such as polyethylene glycol methyl ether methacrylate (PEGMA, $M_{\mathrm{n}} \approx 500 \mathrm{~g} \cdot \mathrm{mol}^{-1}$ ), polylactic acid ethyl methacrylate (PLAsEMA, $M_{\mathrm{n} \text {,avg. }}=474 \mathrm{~g} \cdot \mathrm{mol}^{-}$ ${ }^{1}$ ), and behenyl methacrylate (BeMA, $\left.366 \mathrm{~g} \cdot \mathrm{mol}^{-1}\right)$, estimated bulk $k_{\mathrm{p}}$ values at $25^{\circ} \mathrm{C}$ of 515,543 , and $635 \mathrm{~L} \cdot \mathrm{mol}^{-1} \cdot \mathrm{s}^{-1}$, respectively. ${ }^{36,52,54}$ The assumption of bulk macromonomer concentration to 
yield a minimum $k_{\mathrm{p}}$ is a limiting case; more realistically, the saturated macromonomer concentration could be up to $50-60 \%$ of the bulk value due to the presence of polymer in the mixed micelles, as measured for MMA in poly(MMA) at room temperature, ${ }^{55}$ meaning that the $k_{\mathrm{p}}$ for PCL 2 ChMA at $25^{\circ} \mathrm{C}$ could be as much as $2-3$ times the values for PEGMA, PLAsEMA, or BeMA, and thus among the highest reported bulk methacrylate $k_{\mathrm{p}}$ values. Such an elevated methacrylate $k_{\mathrm{p}}$ could be inflated by a different propagation behavior for the TMAEMI fraction in the compartmentalized phase. Alternatively, it could be that the elevated estimate for bulk $k_{\mathrm{p}}$ is a feature of the micellar environment in which the "looped" or "hairpin" conformation adopted by tail-type cationic surfmers, ${ }^{22,23}$ causes the methacrylate groups at the micelle/water interface to propagate more rapidly than those buried in the micellar core. 


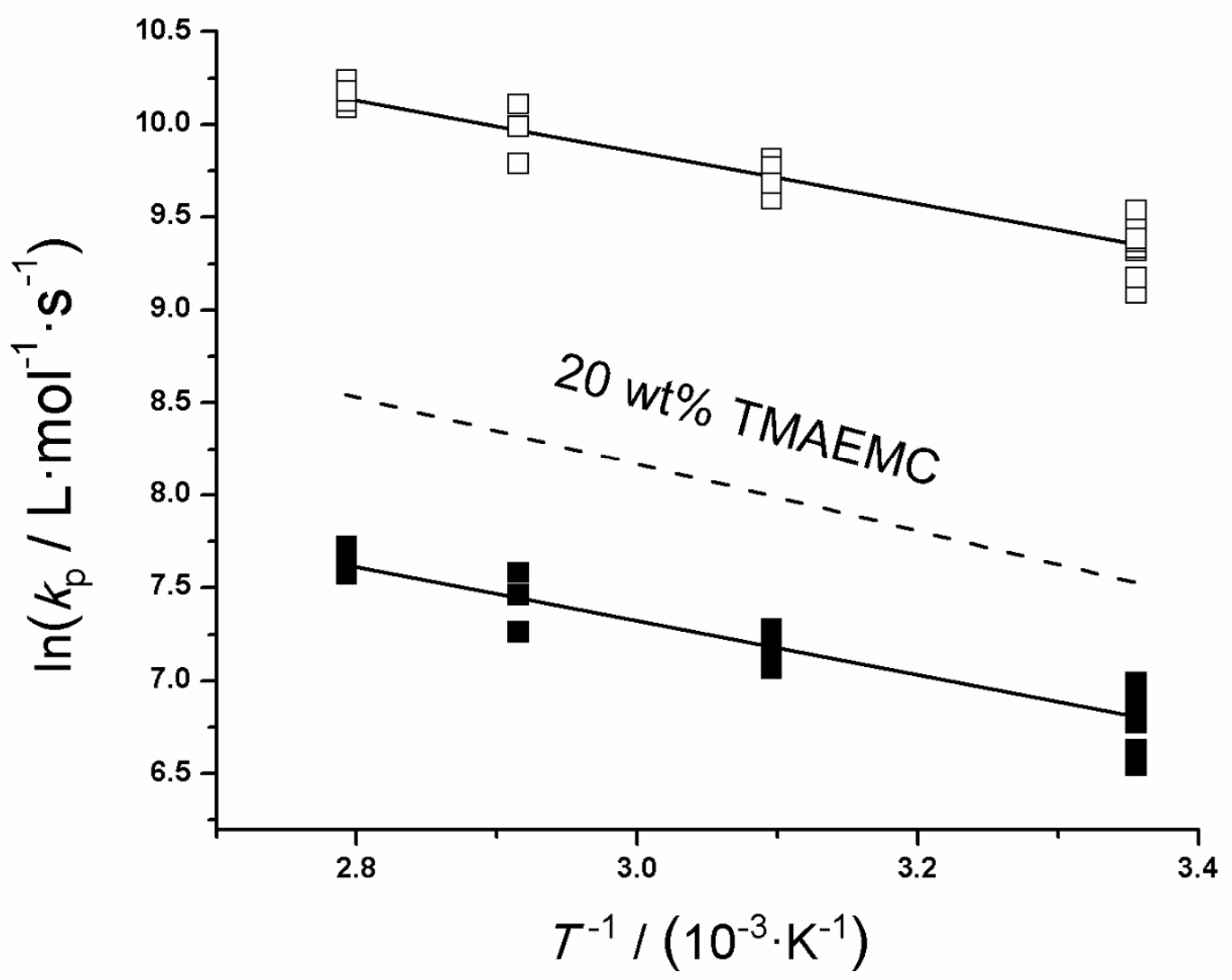

Figure 6: Arrhenius plot for limiting cases of $k_{\mathrm{p}}$, estimated from secondary inflection points of PLP-SEC MMDs for 10 and $20 \mathrm{wt} \% \mathrm{PCL}_{2} \mathrm{ChMA}$ experiments performed at temperatures between 25 and $85{ }^{\circ} \mathrm{C}$, assuming bulk (a) and purely aqueous ( $\square$ ) macromonomer concentrations. The Arrhenius expression for the $k_{\mathrm{p}}$ of $20 \mathrm{wt} \%$ TMAEMC in aqueous solution is provided for reference. ${ }^{[42]}$

\section{Batch Macromonomer Copolymerization}

The PLP-SEC investigations highlighted the complexities of $\mathrm{PCL}_{2} \mathrm{ChMA}$ homopropagation kinetics, and therefore batch experiments were performed to shed more light on the intricacies of $\mathrm{PCL}_{\mathrm{n}}$ ChMA MRP. Furthermore, since a greater diversity of material properties can be achieved through surfmer copolymerization with water soluble comonomers, ${ }^{9}$ the batch studies were extended to AM copolymerization. Using the in situ ${ }^{1} \mathrm{H}$ NMR technique, ${ }^{48,56}$ monomer conversion and composition drift were monitored during batch radical (co)polymerizations of $\mathrm{PCL}_{\mathrm{n}} \mathrm{ChMA}$ 
and $\mathrm{AM}$ in $\mathrm{D}_{2} \mathrm{O}$ at $50{ }^{\circ} \mathrm{C}$ with initial monomer concentrations of 5 and $10 \mathrm{wt} \%$ for $\mathrm{PCL}_{3} \mathrm{ChMA}$ as well as $10 \mathrm{wt} \%$ for $\mathrm{PCL}_{2} \mathrm{ChMA}$ systems. Strong evidence for $\mathrm{PCL}_{n} \mathrm{ChMA}$ compartmentalized propagation is demonstrated by the respective conversion profiles in Figures S10, S11, and S12 in which greater than $90 \%$ conversion is reached more rapidly for $\mathrm{PCL}_{n} \mathrm{ChMA}$ homopropagation than any of the AM homopropagation or copolymerization systems. The weight-average MWs $(M \mathrm{w})$ and dispersities $(\nexists)$ of the final polymer produced from these high conversion batch experiments are summarized by Table S8, with molar mass distributions (MMD) presented as Figures $\mathrm{S} 13, \mathrm{~S} 14$, and $\mathrm{S} 15$. In general, the $M \mathrm{w}$ measured for AM homopolymerizations are larger than for PCL $\mathrm{L}_{\mathrm{n}} \mathrm{ChMA}$ systems, likely because of the higher acrylate compared to methacrylate $k_{\mathrm{p}}{ }^{35}$ In addition, it can be observed that the $M_{\mathrm{w}}$ for copolymerizations containing $\mathrm{AM}$ increases significantly from 5 to $10 \mathrm{wt} \%$ initial monomer content mainly due to the increased AM concentration at the reaction site but also because of the reduced relative importance of backbiting. ${ }^{57}$ Without going into more detail, it should be noted that the MMDs are multimodal and likely represent a complex balance between reactions in both aqueous and compartmentalized phases further complicated by the presence of AM.

The AM/PCL ${ }_{n}$ ChMA copolymer composition behavior can be analyzed from the individual monomer concentrations measured by the situ ${ }^{1} \mathrm{H}$ NMR technique. In contrast to AM copolymerizations with the acrylate analog of $\mathrm{TMAEMC}^{58}$ or ionized acrylic acid, ${ }^{56}$ the monomer composition drift profiles for the 5 and $10 \mathrm{wt} \% n=3 \mathrm{AM} / \mathrm{PCL}_{n} \mathrm{ChMA}$ systems, presented in Figure 7, show no dependence on the initial monomer concentration relative to $\mathrm{D}_{2} \mathrm{O}$ as was also documented for the aqueous copolymerization of AM and non-ionized acrylic acid. ${ }^{48}$ Using both $\mathrm{AM} / \mathrm{PCL}_{3} \mathrm{ChMA}$ data sets in Figure 7, the integrated Mayo-Lewis approach was implemented to estimate apparent monomer reactivity ratios of $r \mathrm{AM}=0.31 \pm 0.03$ and $r$ PCL3ChMA $=8.79 \pm 0.38$; 
these values, which also adequately fit the $\mathrm{AM} / \mathrm{PCL}_{2} \mathrm{ChMA}$ composition drift data, indicate preferential $\mathrm{PCL}_{n} \mathrm{ChMA}$ incorporation at all compositions. The agreement between $\mathrm{AM} / \mathrm{PCL}_{3} \mathrm{ChMA}$ and $\mathrm{AM} / \mathrm{PCL}_{2} \mathrm{ChMA}_{\mathrm{A}}$ monomer composition drifts indicates that the macromonomer reactivity towards AM is independent of the number of PCL units in its side chain, an effect previously documented for the copolymerization of various polyester macromonomers with styrene. ${ }^{53}$

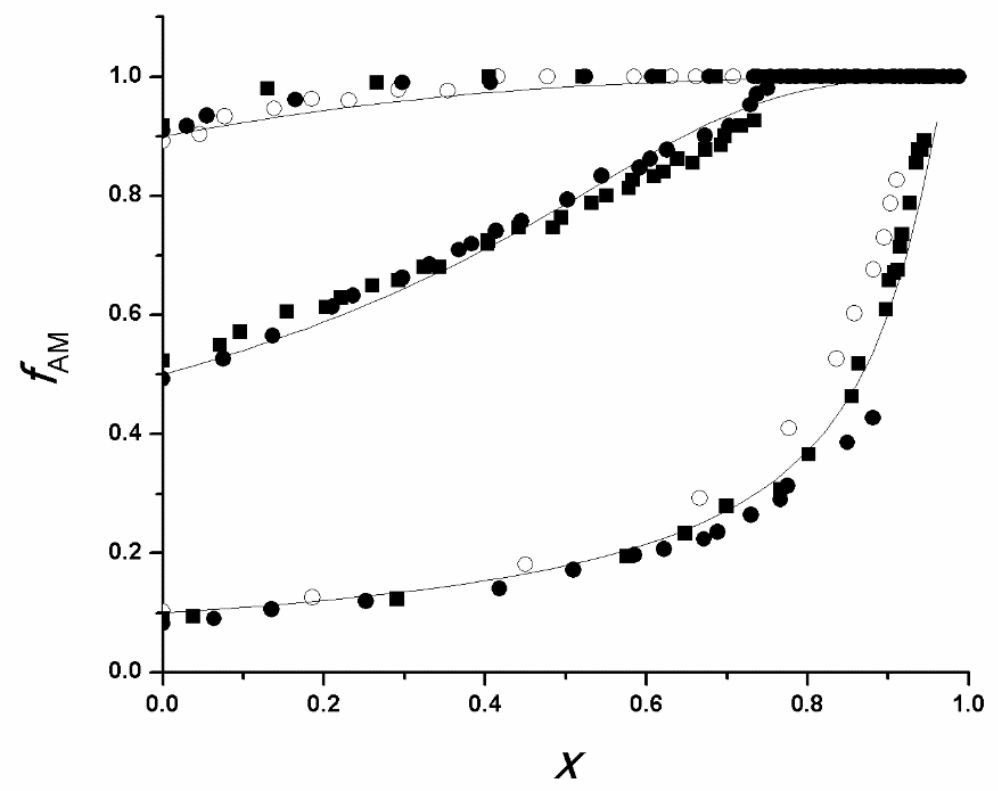

Figure 7: Monomer composition drift plots for $\mathrm{AM} / \mathrm{PCL}_{\mathrm{n}} \mathrm{ChMA}$ copolymerizations at $5 \mathrm{wt} \%$ $(n=3 ; \square)$ and $10 \mathrm{wt} \%(n=3 ; \bullet$ and $n=2 ; \circ)$ in $D_{2} \mathrm{O}$ performed at $50{ }^{\circ} \mathrm{C}$ with $0.22 \mathrm{wt} \% \mathrm{~V}-50$ as initiator. Solid lines represent terminal model reactivity ratios $r_{\mathrm{AM}}=0.31$ and $r_{\text {surfmer }}=8.79$ estimated from the $n=3$ data using the integrated Mayo-Lewis approach.

Previous studies on the incorporation behavior of small amounts of hydrophobic monomer (1-3 mol\%) during micellar radical copolymerization with hydrophilic monomers ascertained that the reaction mechanism is governed by the intrinsic monomer reactivity ratios as well as the micellar effect (high monomer concentration within micelles in conjunction with rapid monomer 
exchange between micelles). ${ }^{13}$ Therefore, it is likely that these reactivity ratios estimated for $\mathrm{AM} / \mathrm{PCL}_{3} \mathrm{ChMA}_{\mathrm{A}}$ copolymerization represent apparent rather than intrinsic values. However, there are similarities to the copolymerization of AM with methyl methacrylate (MMA), whose polymerizable group is the same as that of $\mathrm{PCL}_{\mathrm{n}} \mathrm{ChMA}$, and for which reactivity ratios in dioxane $\left(r_{\mathrm{AM}}=0.90\right.$ and $\left.r_{\mathrm{MMA}}=5.53\right)$ and in cyclohexanone $\left(r_{\mathrm{AM}}=0.65\right.$ and $\left.r_{\mathrm{MMA}}=8.75\right)$ are reported. ${ }^{59}$ Despite potential different solvent effects between organic and aqueous environments, the comparison of $\mathrm{AM} / / \mathrm{PCL}_{3} \mathrm{ChMA}$ and $\mathrm{AM} / \mathrm{MMA}$ systems indicate an inherent tendency for preferential methacrylate incorporation, independent of the micellar effect.

It is interesting to note that monomer consumption for $f_{\mathrm{AM}, 0}=0.5$ copolymerizations (Figures S10 and S11) is markedly slower than for either of the homopropagation systems, and as summarized by Table $\mathrm{S} 9$, the $f_{\mathrm{AM}, 0}=0.5$ systems exhibit the longest inhibition times. In addition, Table S8 shows that the $M \mathrm{w}$ produced by the $f_{\mathrm{AM}, 0}=0.5$ systems are lower than all other $\mathrm{AM} / \mathrm{PCL}_{3} \mathrm{ChMA}$ compositions. Two considerations are presented to better understand the slow copolymerization of equimolar monomer concentrations (i.e., $f_{\mathrm{AM}, 0}=0.5$ ), the situation in which the opportunity for cross-propagation is highest. Assuming that the estimated apparent $r_{\mathrm{Am}}=0.31$ and $r_{\text {surfmer }}=8.79$ apply to aqueous solution propagation, an AM macroradical will preferentially add a PCL ${ }_{n} C h M A$ dissolved in the aqueous phase. Since a subsequent cross-propagation with AM is improbable, the macroradical will prefer to add more $\mathrm{PCL}_{\mathrm{n}} \mathrm{ChMA}$ units (albeit at a slow rate because the aqueous PCLnChMA concentration is significantly lower than that of $\mathrm{AM}$ ) until the macroradical is hydrophobic enough to enter a micelle to continue $\mathrm{PCL}_{\mathrm{n}} \mathrm{ChMA}$ homopropagation. It would follow that it is both kinetically and thermodynamically unfavorable for the growing compartmentalized poly( $\left.\mathrm{PCL}_{n} \mathrm{ChMA}\right)$ chain to add a hydrophilic $\mathrm{AM}$ from the aqueous phase, and therefore an elevated rate of $\mathrm{PCL} \mathrm{L}_{\mathrm{n}} \mathrm{ChMA}$ compartmentalized homopropagation continues, at the 
expense of PCL ${ }_{n}$ ChMA micelle reservoirs. Given that the saturated aqueous concentration of $\mathrm{PCL}_{n} \mathrm{ChMA}$ is the same for all $f_{\mathrm{AM}, 0}$ compositions, the high fraction of AM-PCLnChMA macroradicals produced in the aqueous phase must be responsible for the slow rate of conversion in the $f_{\mathrm{AM}, 0}=0.5$ system. In AM-rich systems $\left(f_{\mathrm{AM}, 0}=0.9\right)$ the PCL ${ }_{n} C h M A$ micelles are quickly depleted such that $\mathrm{AM}$ homopropagation can ensue, while in $\mathrm{AM}$-poor systems $\left(f_{\mathrm{AM}, 0}=0.1\right)$, the ratio of aqueous $P C L_{n} C h M A$ to $\mathrm{AM}$ concentrations is highest such that fewer $\mathrm{AM}-\mathrm{PCL}_{n} \mathrm{ChMA}$ relative to $P C L_{n} C h M A-P C L_{n} C h M A$ macroradicals are produced in the aqueous phase, where it is thermodynamically more favorable for the latter to enter a micelle. This explanation is supported by the large $\oslash$ values for the $f_{\mathrm{AM}, 0}=0.5$ systems summarized by Table $\mathrm{S} 8$ as well as the complex multimodality of the corresponding MMDs presented in Figures S13, S14, and S15.

Also in support of the above interpretation of $\mathrm{AM} / \mathrm{PCL}_{\mathrm{n}} \mathrm{ChMA}$ copolymerization, it could be that the initial equimolar amount of $\mathrm{AM}$ reduces the aqueous $\mathrm{PCL}_{3} \mathrm{ChMA}$ concentration such that macroradicals cannot grow large (hydrophobic) enough to enter a micelle before being terminated in the aqueous phase. However, as shown in Figure S16, neither the surface activity nor the $\mathrm{CMC}_{\text {of }} \mathrm{PCL}_{3} \mathrm{ChMA}$ at room temperature are significantly different in $1 \mathrm{wt} \% \mathrm{AM}$ aqueous solution (the concentration of $\mathrm{AM}$ at the beginning of a $10 \mathrm{wt} \%$ copolymerization with $f_{\mathrm{AM}, 0}=0.5$ ) than in pure $\mathrm{H}_{2} \mathrm{O}$. On the other hand, at concentrations above its $\mathrm{CMC}, \mathrm{PCL}_{3} \mathrm{ChMA}$ suspensions in $1 \mathrm{wt} \%$ AM aqueous solutions were observed to become cloudy after several hours at room temperature, as indicated by the increased particle sizes presented in Figure S17. Since $\mathrm{PCL}_{3} \mathrm{ChMA}$ solutions are stable in $3.4 \mathrm{M} \mathrm{NaCl}$ solutions, it is unlikely that the observed increase in size for $1 \mathrm{wt} \% \mathrm{AM}$ solutions is caused by aggregation resulting from screening of the PCL ${ }_{3}$ ChMA cationic groups. Instead, a specific interaction between AM's primary amide and PCL ${ }_{3} \mathrm{ChMA}$ 's polyester carbonyls could be responsible for increasing the hydrophilicity of 
$\mathrm{PCL}_{3} \mathrm{ChMA}$ micelles, swelling them with $\mathrm{H}_{2} \mathrm{O}$, and making entry of a growing chain more difficult.

\section{Conclusions}

The PLP-SEC technique was implemented to measure $k_{\mathrm{p}} \cdot[M]$ for the micellar radical polymerization of 5,10 , and $20 \mathrm{wt} \% \mathrm{PCL}_{2} \mathrm{ChMA}$ aqueous solutions at $25,50,70$, and $85{ }^{\circ} \mathrm{C}$. Analyses of the PLP experiments are complicated by the fact that PCLnChMA is a distribution of macromonomers which can propagate in both aqueous and compartmentalized phases. At $25{ }^{\circ} \mathrm{C}$, the inflection point locations of the PLP MMDs were unchanged for conversions up to $28 \%, \mathrm{NaCl}$ concentrations up to $3.4 \mathrm{M}$, and photoinitiator type (LiTPO and DMPA with high and low aqueous solubilities, respectively), whereas the MMD inflection points from PLP experiments performed at $85{ }^{\circ} \mathrm{C}$ were sensitive to all these parameters. These findings indicate that at $25{ }^{\circ} \mathrm{C} \mathrm{PCL}_{2} \mathrm{ChMA}$ propagation is predominantly compartmentalized inside the micelles at a saturated macromonomer concentration, whereas at $85^{\circ} \mathrm{C}$ the aqueous phase $k_{\mathrm{p}} \cdot[M]$ contributions are significant. Thus, an absolute value for minimum $k_{\mathrm{p}}$ is calculated, assuming a bulk $\mathrm{PCL}_{2} \mathrm{ChMA}$ concentration, to be $863 \pm 95 \mathrm{~L} \cdot \mathrm{mol}^{-1} \cdot \mathrm{s}^{-1}$ at $25^{\circ} \mathrm{C}$. This bulk $k_{\mathrm{p}}$ estimate is elevated in comparison to other large MW methacrylates such as PEGMA, PLAsEMA, or BeMA, and the value is likely an underestimation of the true $k_{\mathrm{p}}$ for $\mathrm{PCL}_{2} \mathrm{ChMA}$ because of the saturated conditions at $25^{\circ} \mathrm{C}$.

PLP-SEC experiments performed at 50 and $70^{\circ} \mathrm{C}$ under identical conditions yielded higher MW inflection points when DMPA was used as photoinitiator instead of LiTPO. This observation is a clear indication that contributions from aqueous phase propagation, where $k_{\mathrm{p}} \cdot[M]$ must be different than inside the micelles, become increasingly important at higher temperatures, and therefore an appropriate evaluation of the PLP-SEC data should consider the mean lifetime of a 
macroradical in both aqueous and compartmentalized phases. However, the extent to which the locus of polymerization changes as well as the corresponding macromonomer concentrations in the aqueous and compartmentalized phases are unknown and difficult to determine. To better discern the contributions from the aqueous and compartmentalized phases, future PLP-SEC experiments would benefit from temperature dependent $\mathrm{CMC}$ and saturated macromonomer concentration measurements as well as a systematic study of the combined effect of photoinitiator type and $\mathrm{NaCl}$ concentration on $k_{\mathrm{p}} \cdot[M]$. The former is designed to alter the locus of radical generation and the latter can lower the aqueous macromonomer concentration.

Lastly, in situ ${ }^{1} \mathrm{H}$ NMR was used to track monomer composition drift during batch $\mathrm{PCL}_{\mathrm{n}} \mathrm{ChMA}$ copolymerizations with $\mathrm{AM}$ performed at $50{ }^{\circ} \mathrm{C}$ in $\mathrm{D}_{2} \mathrm{O}$. The integrated Mayo-Lewis approach was implemented to estimate apparent reactivity ratios of $r_{\mathrm{AM}}=0.31 \pm 0.03$ and $r$ PCLnChMA $=8.79 \pm 0.38$ which adequately represent monomer composition drifts for initial overall (macro)monomer concentrations of 5 and $10 \mathrm{wt} \%$ for both $n=2$ and $n=3$ macromonomers. An explanation for the markedly slow rates of conversion in the $f_{\mathrm{AM}, 0}=0.5$ copolymerizations is proposed in terms of the fraction of $\mathrm{AM}-\mathrm{PC} \mathrm{L}_{\mathrm{n}} \mathrm{ChMA}$ macroradicals (relative to $\mathrm{PCL}_{n} \mathrm{ChMA}$ PCL ${ }_{n}$ ChMA macroradicals) produced in the aqueous phase which do not favorably cross propagate with AM and can only become hydrophobic enough to enter a $P C L_{n} C h M A$ micelle via addition of another PCLnChMA unit, whose $\mathrm{CMC}$ is low in comparison to the concentration of $\mathrm{AM}$ in the aqueous phase.

\section{Acknowledgements}

The authors thank Dr. Branislav Horváth, Faculty of Pharmacy Comenius University in Bratislava, Slovak Republic for helpful discussions and for carrying out the in situ ${ }^{1} \mathrm{H}$ NMR experiments. T.R. 
gratefully acknowledges $\mathrm{PhD}$ scholarships from the Natural Sciences and Engineering Research Council of Canada as well as the National Scholarship Programme of the Slovak Republic.

\section{References}

(1) Jaeger, W.; Bohrisch, J.; Laschewsky, A. Prog. Polym. Sci. 2010, 35, 511.

(2) Vedoy, D. R. L.; Soares, J. B. P. Can. J. Chem. Eng. 2015, 93, 888.

(3) Wang, C.; Harbottle, D.; Liu, Q.; Xu, Z. Miner. Eng. 2014, 58, 113.

(4) Sharma, S. K.; Chauhan, G. S.; Gupta, R.; Ahn, J.-H. J. Mater. Sci. Mater. Med. 2009, 21, 717.

(5) Kuo, C.-H.; Leon, L.; Chung, E. J.; Huang, R.-T.; Sontag, T. J.; Reardon, C. A.; Getz, G. S.; Tirrell, M.; Fang, Y. J. Mater. Chem. B 2014, 2, 8142.

(6) Wever, D. A. Z.; Picchioni, F.; Broekhuis, A. A. Prog. Polym. Sci. 2011, 36, 1558.

(7) González García, G.; Kreft, T.; Alb, A. M.; de la Cal, J. C.; Asua, J. M.; Reed, W. F. J. Phys. Chem. B 2008, 112, 14597.

(8) Losada, R.; Wandrey, C. Macromolecules 2009, 42, 3285.

(9) Candau, F.; Selb, J. Adv. Colloid Interface Sci. 1999, 79, 149.

(10) Stähler, K.; Selb, J.; Candau, F. Mater. Sci. Eng.: C 1999, 10, 171.

(11) Summers, M.; Eastoe, J. Adv. Colloid Interface Sci. 2003, 100-102, 137.

(12) Joynes, D.; Sherrington, D. C. Polymer 1996, 37, 1453.

(13) Lacík, I.; Selb, J.; Candau, F. Polymer 1995, 36, 3197.

(14) Cochin, D.; Zana, R.; Candau, F. Macromolecules 1993, 26, 5765.

(15) Hamid, S. M.; Sherrington, D. C. Polymer 1987, 28, 332.

(16) Cochin, D.; Candau, F.; Zana, R. Macromolecules 1993, 26, 5755.

(17) Hamid, S.; Sherrington, D. Chem. Commun. 1986, 936.

(18) Chatjaroenporn, K.; Baker, R. W.; FitzGerald, P. A.; Warr, G. G. Langmuir 2010, 26, 11715.

(19) Chatjaroenporn, K.; Baker, R. W.; FitzGerald, P. A.; Warr, G. G. J. Colloid Interface Sci. 2009, 336, 449 .

(20) FitzGerald, P. A.; McDonald, D. M.; Warr, G. G. Soft Matter 2013, 9, 2711.

(21) FitzGerald, P. A.; Warr, G. G. Adv. Colloid Interface Sci. 2012, 179-182, 14.

(22) Hamid, S. M.; Sherrington, D. C. Polymer 1987, 28, 325. 
(23) FitzGerald, P. A.; Chatjaroenporn, K.; Zhang, X.; Warr, G. G. Langmuir 2011, 27, 11852.

(24) Beuermann, S.; Buback, M. Prog. Polym. Sci. 2002, 27, 191.

(25) Beuermann, S.; Buback, M.; Davis, T. P.; Gilbert, R. G.; Hutchinson, R. A.; Olaj, O. F.; Russell, G. T.; Schweer, J.; van Herk, A. M. Macromol. Chem. Phys. 1997, 198, 1545.

(26) Beuermann, S.; Buback, M.; Davis, T. P.; Gilbert, R. G.; Hutchinson, R. A.; Kajiwara, A.; Klumperman, B.; Russell, G. T. Macromol. Chem. Phys. 2000, 201, 1355.

(27) Lacík, I.; Stach, M.; Kasák, P.; Semak, V.; Uhelská, L.; Chovancová, A.; Reinhold, G.; Kilz, P.; Delaittre, G.; Charleux, B.; Chaduc, I.; D'Agosto, F.; Lansalot, M.; Gaborieau, M.; Castignolles, P.; Gilbert, R. G.; Szablan, Z.; Barner-Kowollik, C.; Hesse, P.; Buback, M. Macromol. Chem. Phys. 2015, 216, 23.

(28) Buback, M. Macromol. Symp. 2009, 275-276, 90.

(29) Stach, M.; Lacík, I.; Kasák, P.; Chorvát, D.; Saunders, A. J.; Santanakrishnan, S.; Hutchinson, R. A. Macromol. Chem. Phys. 2010, 211, 580.

(30) Stach, M.; Lacík, I.; Chorvát, D.; Buback, M.; Hesse, P.; Hutchinson, R. A.; Tang, L. Macromolecules 2008, 41, 5174.

(31) Lacík, I.; Beuermann, S.; Buback, M. Macromolecules 2003, 36, 9355.

(32) Beuermann, S.; Buback, M.; Hesse, P.; Kukučková, S.; Lacık, I. Macromol. Symp. 2007, $248,41$.

(33) Beuermann, S.; Buback, M.; Hesse, P.; Lacík, I. Macromolecules 2006, 39, 184.

(34) Lacík, I.; Beuermann, S.; Buback, M. Macromolecules 2001, 34, 6224.

(35) Lacík, I.; Chovancová, A.; Uhelská, L.; Preusser, C.; Hutchinson, R. A.; Buback, M. Macromolecules 2016, 49, 3244.

(36) Smolne, S.; Weber, S.; Buback, M. Macromol. Chem. Phys. 2016, 217, 2391.

(37) Lacík, I.; Učňová, L.; Kukučková, S.; Buback, M.; Hesse, P.; Beuermann, S. Macromolecules 2009, 42, 7753.

(38) Beuermann, S.; Paquet, D. A.; McMinn, J. H.; Hutchinson, R. A. Macromolecules 1996, $29,4206$.

(39) Vana, P.; Yee, L. H.; Davis, T. P. Macromolecules 2002, 35, 3008.

(40) Drawe, P.; Buback, M. Macromol. Theory Simul. 2016, 25, 74.

(41) Kattner, H.; Drawe, P.; Buback, M. Macromol. Chem. Phys. 2015, 216, 1737.

(42) Drawe, P.; Kattner, H.; Buback, M. Macromol. Chem. Phys. 2016, 217, 2755.

(43) Manders, B. G.; Van Herk, A. M.; German, A. L.; Sarnecki, J.; Schomäcker, R.; Schweer, J. Makromol. Chem. Rapid Comm. 1993, 14, 693. 
(44) Schweer, J.; van Herk, A. M.; Pijpers, R. J.; Manders, B. G.; German, A. L. Macromol. Symp. 1995, 92, 31.

(45) van Herk, A. M.; de Brouwer, H.; Manders, B. G.; Luthjens, L. H.; Hom, M. L.; Hummel, A. Macromolecules 1996, 29, 1027.

(46) Jung, M.; van Casteren, I.; Monteiro, M. J.; van Herk, A. M.; German, A. L. Macromolecules 2000, 33, 3620.

(47) Rooney, T. R.; Gumfekar, S. P.; Soares, J. B. P.; Hutchinson, R. A. Macromol. Mater. Eng. 2016, 301, 1248.

(48) Preusser, C.; Hutchinson, R. A. Macromol. Symp. 2013, 333, 122.

(49) da Silva, G. C.; Rossi, C. G. F. T.; Dantas Neto, A. A.; Dantas, T. N. C.; Fonseca, J. L. C. Colloids Surf. A 2011, 377, 35.

(50) Drawe, P.; Buback, M.; Lacík, I. Macromol. Chem. Phys. 2015, 217, 1333.

(51) Kattner, H.; Drawe, P.; Buback, M. Macromolecules 2017, 50, 1368.

(52) Rooney, T. R.; Moscatelli, D.; Hutchinson, R. A. React. Chem. Eng. 2017, 2, 487.

(53) Rooney, T. R.; Monyatsi, O.; Hutchinson, R. A. Macromolecules 2017, 50, 784.

(54) Haehnel, A. P.; Schneider-Baumann, M.; Hiltebrandt, K. U.; Misske, A. M.; BarnerKowollik, C. Macromolecules 2013, 46, 15.

(55) Gardon, J. L. J. Polym. Sci. Part A: Polym. Chem. 1968, 6, 2859.

(56) Preusser, C.; Ezenwajiaku, I. H.; Hutchinson, R. A. Macromolecules 2016, 49, 4746.

(57) Preusser, C.; Chovancová, A.; Lacík, I.; Hutchinson, R. A. Macromol. React. Eng. 2016, $10,490$.

(58) Cuccato, D.; Storti, G.; Morbidelli, M. Macromolecules 2015, 48, 5076.

(59) Kaim, A.; Oracz, P. Polymer 1997, 38, 2221. 